\title{
A sense of place: transcriptomics identifies environmental signatures in Cabernet Sauvignon berry skins in the late stages of ripening
}

\author{
Grant R. Cramer ${ }^{1 *}$ (D, Noé Cochetel ${ }^{1}$, Ryan Ghan ${ }^{1}$, Agnès Destrac-Irvine ${ }^{2}$ and Serge Delrot ${ }^{2}$
}

\begin{abstract}
Background: Grape berry ripening is influenced by climate, the main component of the "terroir" of a place. Light and temperature are major factors in the vineyard that affect berry development and fruit metabolite composition.

Results: To better understand the effect of "place" on transcript abundance during the late stages of berry ripening, Cabernet Sauvignon berries grown in Bordeaux and Reno were compared at similar sugar levels (19 to $26^{\circ}$ Brix (total soluble solids)). Day temperatures were warmer and night temperatures were cooler in Reno. ${ }^{\circ}$ Brix was lower in Bordeaux berries compared to Reno at maturity levels considered optimum for harvest. RNA-Seq analysis identified 5528 differentially expressed genes between Bordeaux and Reno grape skins at $22^{\circ}$ Brix. Weighted Gene Coexpression Network Analysis for all expressed transcripts for all four ${ }^{\circ}$ Brix levels measured indicated that the majority (75\%) of transcript expression differed significantly between the two locations. Top gene ontology categories for the common transcript sets were translation, photosynthesis, DNA metabolism and catabolism. Top gene ontology categories for the differentially expressed genes at $22^{\circ} \mathrm{Brix}$ involved response to stimulus, biosynthesis and response to stress. Some differentially expressed genes encoded terpene synthases, cell wall enzymes, kinases, transporters, transcription factors and photoreceptors. Most circadian clock genes had higher transcript abundance in Bordeaux. Bordeaux berries had higher transcript abundance with differentially expressed genes associated with seed dormancy, light, auxin, ethylene signaling, powdery mildew infection, phenylpropanoid, carotenoid and terpenoid metabolism, whereas Reno berries were enriched with differentially expressed genes involved in water deprivation, cold response, ABA signaling and iron homeostasis.

Conclusions: Transcript abundance profiles in the berry skins at maturity were highly dynamic. RNA-Seq analysis identified a smaller (25\% of total) common core set of ripening genes that appear not to depend on rootstock, vineyard management, plant age, soil and climatic conditions. Much of the gene expression differed between the two locations and could be associated with multiple differences in environmental conditions that may have affected the berries in the two locations; some of these genes may be potentially controlled in different ways by the vinegrower to adjust final berry composition and reach a desired result.
\end{abstract}

Keywords: Abiotic stress, Biotic stress, Grape berry development, RNA-Seq, Transcriptomics, Vitis vinifera L

\footnotetext{
*Correspondence: cramer@unr.edu

'Department of Biochemistry and Molecular Biology, University of Nevada,

Reno, NV 89557, USA

Full list of author information is available at the end of the article
}

(c) The Author(s). 2020 Open Access This article is distributed under the terms of the Creative Commons Attribution 4.0 International License (http://creativecommons.org/licenses/by/4.0/), which permits unrestricted use, distribution, and reproduction in any medium, provided you give appropriate credit to the original author(s) and the source, provide a link to the Creative Commons license, and indicate if changes were made. The Creative Commons Public Domain Dedication waiver (http://creativecommons.org/publicdomain/zero/1.0/) applies to the data made available in this article, unless otherwise stated. 


\section{Background}

Vitis vinifera grapevines originated approximately 65 million years ago from Eurasia and have been cultivated for at least the last 8000 years for its fruits that are crushed to make wine [1]. Grapevines are now grown throughout the world in many kinds of environments.

Grape berry development is a complex process involving three developmental phases and multiple hormones $[2,3]$. It is in the latter ripening phase that many compounds involved in flavor and aromas are synthesized, conjugated or catabolized. Most of these compounds reside in the skin of the berry and seem to develop in the very last stages of berry development [4-6].

Aroma and flavor are important sensory components of wine. They are derived from multiple classes of compounds in grapes including important volatile compounds from the grape and from yeast metabolism during grape fermentation $[5,6]$. Each grape cultivar produces a unique set of volatile and flavor compounds at varying concentration that represents its wine typicity or typical cultivar characteristics [6]. Esters and terpenes are volatile compound chemical classes largely responsible for the fruity and floral aromas in wines [5, 6]. Esters are largely produced during yeast fermentation from grape-derived products such as aliphatic alcohols and aldehydes [7, 8]. Grape lipoxygenases are thought to provide the six carbon precursors from fatty acids for the synthesis of the fruity aroma, hexyl acetate [8], in yeast during wine fermentation. Terpenes mostly originate from the grapes and are found in both the free and bound (glycosylated) forms. Both plant fatty acid and terpenoid metabolism pathways are very sensitive to the environment [9-13].

Climate has large effects on berry development and composition [14-16]. Besides grape genetics other factors may influence metabolite composition including the local grape berry microbiome [17], the soil type [15] and the rootstock [18-22]. While there is evidence that rootstock can affect fruit composition and transcript abundance, this effect appears to be minor relative to other environmental factors $[18,19,21]$. Many cultural practices used by the grape grower may directly or indirectly affect the environment sensed by the grapevine (row orientation, planting density, pruning, leaf removal, etc.). Temperature and light are major contributors to "terroir". Terroir refers to the environmental effects on grapes and how it contributes distinctive characteristics to the typicity of a wine $[2,14,15,23]$. The terroir term includes biotic and abiotic factors, soil environments as well as the viticultural practices. In the present work, we will use the term "place" to address all of the above except for the viticultural practices.

Recently, a transcriptomic approach was used to elucidate the common gene subnetworks of the late stages of berry development when grapes are normally harvested at their peak maturity [4]. One of the major subnetworks associated with ripening involved autophagy, catabolism, RNA splicing, proteolysis, chromosome organization and the circadian clock. An integrated model was constructed to link light sensing with the circadian clock highlighting the importance of the light environment on berry development. In this report, in order to get a better understanding of how much of the gene expression in Cabernet Sauvignon berry skin could be attributed to environmental influences, we tested the hypothesis that there would be significant differences in gene expression during the late stages of Cabernet Sauvignon berry ripening between two widely different locations: one in Reno, NV, USA (RNO) and the other in Bordeaux, France (BOD). The analysis revealed a core set of genes that did not depend on location, climate, vineyard management, grafting and soil properties. Also, the analysis revealed key genes that are differentially expressed between the two locations. Some of these differences were linked to the effects of temperature and other environmental factors known to affect aromatic and other quality-trait-associated pathways. Many gene families were differentially expressed and may provide useful levers for the vinegrower to adjust berry composition. Among others, these families encompassed genes involved in amino acid and phenylpropanoid metabolism, as well as aroma and flavor synthesis.

\section{Results}

\section{Background data for a "Sense of Place"}

To test the hypothesis that the transcript abundance of grape berries during the late stages of ripening differed in two locations with widely different environmental conditions, we compared the transcript abundance of grape berry skins in BOD and RNO. The vineyards were originally planted in RNO in 2004 and in BOD in 2009. The RNO vines were grown on their own roots, whereas the $\mathrm{BOD}$ vines were grafted on to $\mathrm{SO} 4$ rootstock. A vertical shoot positioning trellis design was used in both locations. There were a number environmental variables that differed between the two locations. BOD is located at a slightly more northern latitude than RNO. This resulted in slightly longer day lengths in BOD at the beginning of harvest and slightly shorter at the end of harvest (Table 1). On the final harvest dates, the day length differed between RNO and BOD by about $30 \mathrm{~min}$.

RNO had warmer average monthly maximum temperatures than that in BOD, but minimum September temperatures were cooler in RNO (Table 1). Thus, RNO had a larger average daily day/night temperature differential of $20^{\circ} \mathrm{C}$, whereas BOD had a smaller average daily day/ night temperature differential of $10{ }^{\circ} \mathrm{C}$ during the harvest periods. RNO had warmer day temperatures by about 
Table 1 Environmental variables for the harvest times in BOD and RNO. Grapes were harvested in RNO from September 10 to 26 , 2012 and in BOD from September 17 to October 8, 2013

\begin{tabular}{|c|c|c|}
\hline Environmental Variable & BOD (2013) & RNO (2012) \\
\hline Elevation (m) & 25 & 1373 \\
\hline Average Daily Solar Radiation ( $\mathrm{kW}-\mathrm{hr} \mathrm{m}^{-2}$ ) & 1.17 & 5.86 \\
\hline Day length Starting Harvest Date & $12: 25: 36$ & $12: 38: 34$ \\
\hline Day length Ending Harvest Date & $11: 20: 57$ & 11:57:37 \\
\hline Maximum Temperature Starting Harvest Date & 19 & 30.5 \\
\hline Minimum Temperature Starting Harvest Date & 13 & 13.9 \\
\hline Maximum Temperature Ending Harvest Date & 18 & 27.8 \\
\hline Minimum Temperature Ending Harvest Date $\left({ }^{\circ} \mathrm{C}\right)$ & 11 & 6.7 \\
\hline Ave September Maximum Temperature $\left({ }^{\circ} \mathrm{C}\right)$ & 23.9 & 30.2 \\
\hline Ave September Minimum Temperature $\left({ }^{\circ} \mathrm{C}\right)$ & 13.9 & 10.2 \\
\hline Latitude & $44^{\circ} 47^{\prime} 23.83^{\prime \prime} \mathrm{N}$ & $39^{\circ} 52^{\prime} 96^{\prime \prime} \mathrm{N}$ \\
\hline Longitude & $0^{\circ} 34^{\prime} 39.3^{\prime \prime} \mathrm{W}$ & $119^{\circ} 81^{\prime} 38^{\prime \prime} \mathrm{W}$ \\
\hline September Precipitation (mm) & 65.5 & 2.03 \\
\hline Average Monthly Relative Humidity (\%) & 74 & 34 \\
\hline Soil Type & Gravelly soil & Sandy Loam \\
\hline Soil pH & 6.2 & 6.7 \\
\hline Soil Fe $\left(\mu g g^{-1}\right)$ & 193 & 38 \\
\hline Root stock & $\mathrm{SO} 4$ & Own-rooted \\
\hline
\end{tabular}

$6^{\circ} \mathrm{C}$ and cooler night temperatures by about $4{ }^{\circ} \mathrm{C}$ than that of BOD.

The RNO vineyard location was much drier than the BOD vineyard location (Table 1 ). The monthly precipitation totals for RNO in September were $2.03 \mathrm{~mm}$ whereas it was $65.5 \mathrm{~mm}$ in BOD; the average relative humidities were 34 and $74 \%$ for RNO and BOD, respectively. The soil at the RNO vineyard was a deep sandy loam with a $\mathrm{pH}$ of 6.7; the BOD vineyard was a gravelly soil with a $\mathrm{pH}$ of 6.2. No pathogens, nutrient deficiencies or toxicity symptoms were observed on or in the vines at either site.

\section{Transcriptomics}

The analysis of transcript profiles of Cabernet Sauvignon grapes harvested in RNO in September of 2012 was previously described [4]. Individual berry skins were separated immediately from the whole berry and the individual total soluble solids ( ${ }^{\circ}$ Brix) level of the berry, which is mostly composed of sugars, was determined. The Cabernet Sauvignon berry skins from BOD were harvested in a similar manner as the RNO berry skins. The berry skins in BOD were harvested from midway in September, 2013 until the first week of October (Table 1). The berry skins were separated and the ${ }^{\circ}$ Brix analyzed in the same manner as that in RNO. Grapes were harvested at a lower ${ }^{\circ}$ Brix range in BOD (19.5 to $22.5^{\circ}$ Brix) than in $\mathrm{RNO}$ (20 to $26^{\circ}$ Brix) because fruit maturity for making wine is typically reached in the $B O D$ region at a lower sugar level.

Transcript abundance of the RNA-Seq reads from both RNO and BOD was estimated using Salmon software [24] with the assembly and gene model annotation of Cabernet Sauvignon [25, 26]. The TPM (transcripts per million) were computed for each gene from each experimental replicate $(n=3)$ from berry skins at different sugar levels ranging from 19 to $26^{\circ}$ Brix (Additional file 1 ). Principal component analysis of the transcriptomic data showed clear grouping of experimental replicates with the largest separation by location (principal component $1(\mathrm{PC} 1)=51 \%$ variance) and then ${ }^{\circ}$ Brix (principal component $2(\mathrm{PC} 2)=22 \%$ variance $)$ of the berry skin samples (Fig. 1).

To get different perspectives of the data, three approaches were used to further analyze the transcriptomic data. One focused on expression at one similar sugar level in both locations. Another identified a common set of genes whose transcript abundance changed in both locations. And the third one was a more comprehensive network analysis using all of the sugar levels and the two locations.

We chose two very similar sugar levels to determine the differential gene expression between the two locations, since sugar levels were not exactly the same at harvest. We identified 5528 differentially expressed genes (DEGs, at an FDR padj-value $<0.05$ ) between the 


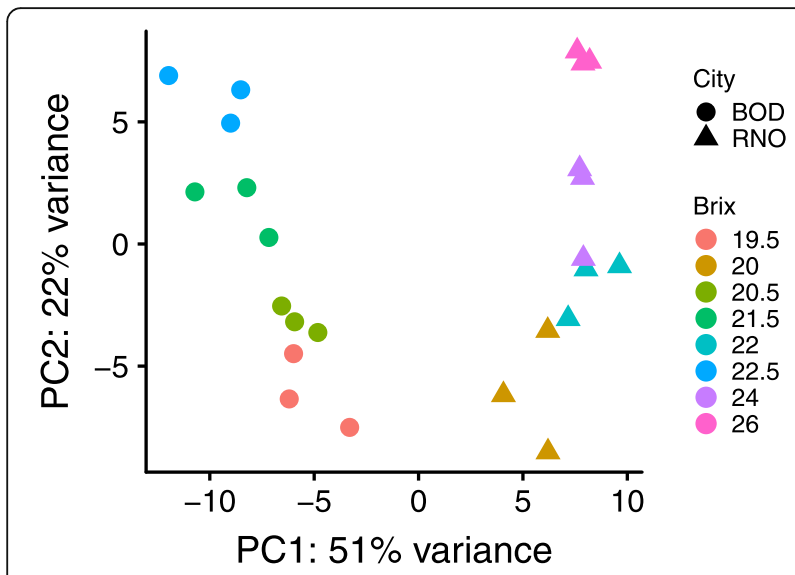

Fig. 1 Principal component analysis of the transcriptomic data from berry skin samples at different ${ }^{\circ} \mathrm{Brix}$ levels from BOD and RNO

two locations in approach 1 at the sugar level closest to the $22^{\circ}$ Brix level $\left(21.5^{\circ}\right.$ Brix in BOD and $22^{\circ}$ Brix in RNO) using DESeq2 [27] (Additional file 2). DEGs will refer to this set of differentially expressed genes throughout this manuscript. Gene set enrichment analysis using topGO determined the top gene ontology $(\mathrm{GO})$ categories for biological processes for these 5528 genes (Additional file 3). Based on the number of genes identified, the top GO categories were cellular metabolic process (3126 genes, padj-value $=2.3 \mathrm{E}-03)$, biosynthetic process (2371 genes, padj-value $=7.7 \mathrm{E}-09)$, and response to stimulus (2324 genes, padj-value $=1.21 \mathrm{E}-26)$. Other important and highly significant categories were response to stress $(1514$ genes, padj-value $=5.69 \mathrm{E}-24)$ and developmental process $(1280$ genes, corrected $p$-value $=$ 8.09E-12). There were $910 \mathrm{GO}$ categories in total that were significantly enriched (Additional file 3). The relationship between the top $25 \mathrm{GO}$ categories can be seen in Additional file 4. We use the term "significantly" throughout this text to mean statistically significant at or below a padj-value of 0.05 . Amongst the top stimulus subcategories with the largest number of genes were response to abiotic stimulus (950 genes; padj-value $=9.1 \mathrm{E}$ 29), response to endogenous stimulus (835 genes, padjvalue $=1.43 \mathrm{E}-21 ; 256$ of which were related to response to abscisic acid), response to external stimulus (719 genes, padj-value $=1.08 \mathrm{E}-24)$, and biotic stimulus $(520$ genes, padj-value $=5.29 \mathrm{E}-22$ ). Some other significant environmental stimuli GO categories included response to light stimulus (234 genes), response to osmotic stress (171 genes), and response to temperature stimulus (158 genes).

In approach 2, we examined which gene expression was changing with ${ }^{\circ}$ Brix level in both locations to identify a common set of genes differentially expressed during berry development with very different environmental conditions. The significant differences in transcript abundance in each location was determined with DESeq 2 using the lowest ${ }^{\circ}$ Brix sampling as the control. For example, the control sample in RNO was the lowest sugar sampling at $20^{\circ} \mathrm{Brix}$; the transcript abundance of the three higher ${ }^{\circ}$ Brix samplings were compared to the transcript abundance of the control. The genes that had significantly different transcript abundance relative to control in at least one of the comparisons were identified in RNO and BOD. These gene lists were compared and the common gene set consisting of 1985 genes for both locations was determined (ap2 tab in Additional file 5). Comparing this common gene list (ap2) to the DEGs from approach 1 identified 907 genes that were common to both sets, indicating that this subset was differentially expressed between the locations at $22^{\circ}$ Brix. The other 1078 genes did not differ significantly between locations. This 1078 gene subset list can be found in Additional file 5 (ap2-ap1 tab). The GO categories most enriched in this gene set included response to inorganic substance, response to abiotic stimulus and drug metabolic process.

In approach 3, using a more powerful approach to finely distinguish the expression data for all sugar levels, Weighted Gene Coexpression Network Analysis (WGCNA) identified gene sets common to (based upon correlation) and different gene expression profiles between BOD and RNO. All expressed genes for all ${ }^{\circ}$ Brix levels (Additional file 1) were used in this analysis. Additional details of the analysis are described in the Materials and Methods section. Twenty-one modules or gene subnetworks were defined (Additional file 6) and a heat map was generated displaying the module-trait relationships (Additional file 7). The grey module is not a real module but a place to put all genes not fitting into a real module; thus, it was not counted as one of the twenty-one gene modules above. Eight modules had similar gene expression profiles for BOD and RNO (padj-value >0.05); these included cyan, midnightblue, pink, green yellow, salmon, blue, grey60, and royalblue. This gene set consisted of 8017 genes (see ap3 tab in Additional file 5 for the gene list). Comparing this common gene set from the WGCNA with the DEGs from approach 1 revealed that 524 genes in common were found in both sets. This subset was removed from the WGCNA to produce a gene list of 7492 common to both locations and not differing in their transcript abundance at $22^{\circ}$ Brix (ap2-ap1). This represents $25 \%$ of the total 29,929 genes in all of the modules. This gene set was compared with the ap2-ap1 gene set from approach 1 and 845 genes were found in common in both sets. The remainder from ap2-ap1 provided an additional 232 genes to the common set of genes from ap3-ap1 not affected by location giving a total number of 7724 genes, representing $25.8 \%$ of the genes expressed. This gene set is listed in ap2-ap1_union ap3-ap1 tab in Additional file 5. The GO categories most enriched in this gene set included general categories such as 
organic substance biosynthetic process and organelle organization. There were 785 enriched GO categories in total.

In approach 3, further analysis of the gene modules using gene set enrichment analysis was performed with genes that had a $\mathrm{kME}>0.80$ for each module in the WGCNA (Additional file 8). The similar gene sets in common with both locations with decreasing transcript abundance as sugar levels increased (negative correlation with ${ }^{\circ}$ Brix) were enriched with the GO categories involving growth and water transport (blue module), and translation (grey60 module). The common gene sets with increasing transcript abundance as sugar levels increased were enriched with the GO categories involving gene silencing (cyan module), aromatic compound metabolism (midnight blue), organic substance catabolism (pink module), and DNA metabolism (salmon).

Most modules were positively or negatively correlated with BOD and RNO berries (e.g. black, yellow, red, turquoise, etc.). The turquoise module was the largest module and consisted of 5029 genes; it had the most positive and negative correlations for BOD and RNO, respectively (Additional file 7). This gene set was similar to the DEGs defined by DESeq2 with the largest differences between BOD and RNO at $22^{\circ}$ Brix. Gene set enrichment analysis of genes within the turquoise module having a $\mathrm{kME}$ of 0.80 or higher (1090 genes) revealed many common GO categories with the DEGs (Additional file 8); 81\% (481 of 594 ) of the GO categories from the turquoise module subset were also found in the 910 GO categories of the DEGs ( $53 \%$ of total). Some of the most enriched GO categories in the turquoise module were organic acid metabolism, flavonoid metabolism, lipid biosynthesis, response to abiotic stimulus, isoprenoid metabolism, response to light stimulus and photosynthesis. The gene expression profiles of this module declined in transcript abundance with increasing sugar levels (negative correlation with ${ }^{\circ} \mathrm{Brix}$ ).

The yellow module was another large module (3008 genes) that was the second most positively correlated with BOD. This module was highly enriched with GO categories involving biosynthesis, defense responses and catabolic processes. The WRKY75 gene (g104630; this g\# term is used as an abbreviated gene loci name in the Cabernet Sauvignon genome throughout this paper) was in the top 4 hub genes $(\mathrm{kME}=0.97)$ in the yellow module (Additional file 6). WRKY75 is a transcription factor that positively regulates leaf senescence. It is induced by ethylene, ROS (reactive oxygen species) and SA (salicylic acid) and is a direct target of EIN3 (ethylene insensitive 3) [28].

The green (2287 genes) and brown (4147 genes) modules were also large modules that were most positively correlated with RNO (0.92 and 0.9, respectively). The green module was highly enriched in the GO category involving response to chemical. The brown module was highly enriched in GO categories involving multiple catabolic processes.

Thus, the WGCNA results, which utilized all of the expressed genes from all ${ }^{\circ}$ Brix levels were consistent with the DESeq2 results that only compared transcript abundances at $22^{\circ}$ Brix or between locations. The WGCNA results were more comprehensive and complemented the results of approaches 1 and 2 by identifying hub genes and gene subnetworks. These subnetworks were linked and further defined by their highly correlated coexpression profiles and enriched GOs.

\section{Transcriptomic profiles dynamically changing with sugar levels}

DEGs with largest increases in transcript abundance between sugar levels

As a first approach to examining the 5528 DEG dataset, differences between the transcript abundance in berries with the lowest and highest ${ }^{\circ} \mathrm{Brix}$ levels at the two locations were determined (Additional file 2). Eight examples of the many DEGs with the largest transcript abundance differences from BOD and RNO (EXL2 (exordium like 2, g068700), HB12 (homeobox 12, g223410), BSMT1 (benzoate/salicylate methyltransferase 1, g336810), HAD (haloacid dehalogenase-like hydrolase protein, g070140), STS24 (stilbene synthase 24, g435870), NAC073 (NAC domain containing protein 73, g125400), TPS35 (terpene synthase $35, \mathrm{~g} 087040$ ), and MAT3 (methionine adenosyltransferase 3, g013310)) were selected and are presented in Fig. 2. The major point of showing this plot is to highlight the general trends of continuously increasing transcript abundance with sugar levels for these genes; half of these genes start at similar transcript abundance levels around $20^{\circ}$ Brix for both BOD and RNO berries and increase in transcript abundance at a higher rate in BOD grapes as sugar levels increase. The other half increased at approximately the same rate for both locations but had higher amounts at the BOD location at the same sugar levels. These data were fitted by linear regression to compare the slopes of the lines. The slopes were significantly higher for EXL2, BSMT1, STS24, and TPS35 for BOD as compared to RNO berries, but not for the other four genes (data not shown). The significantly increased rate of change for transcript abundance in the BOD berries indicated that the berries in BOD may have ripened at a faster rate relative to sugar level.

To get deeper insights into these dynamic gene sets from BOD and RNO, gene set enrichment analysis of the top 400 DEGs with the greatest increase in transcript abundance from the lowest sugar level to the highest sugar level was performed for each location. The top 400 DEGs for BOD berries were highly enriched in biosynthetic processes involving amino acid and phenylpropanoid metabolism 

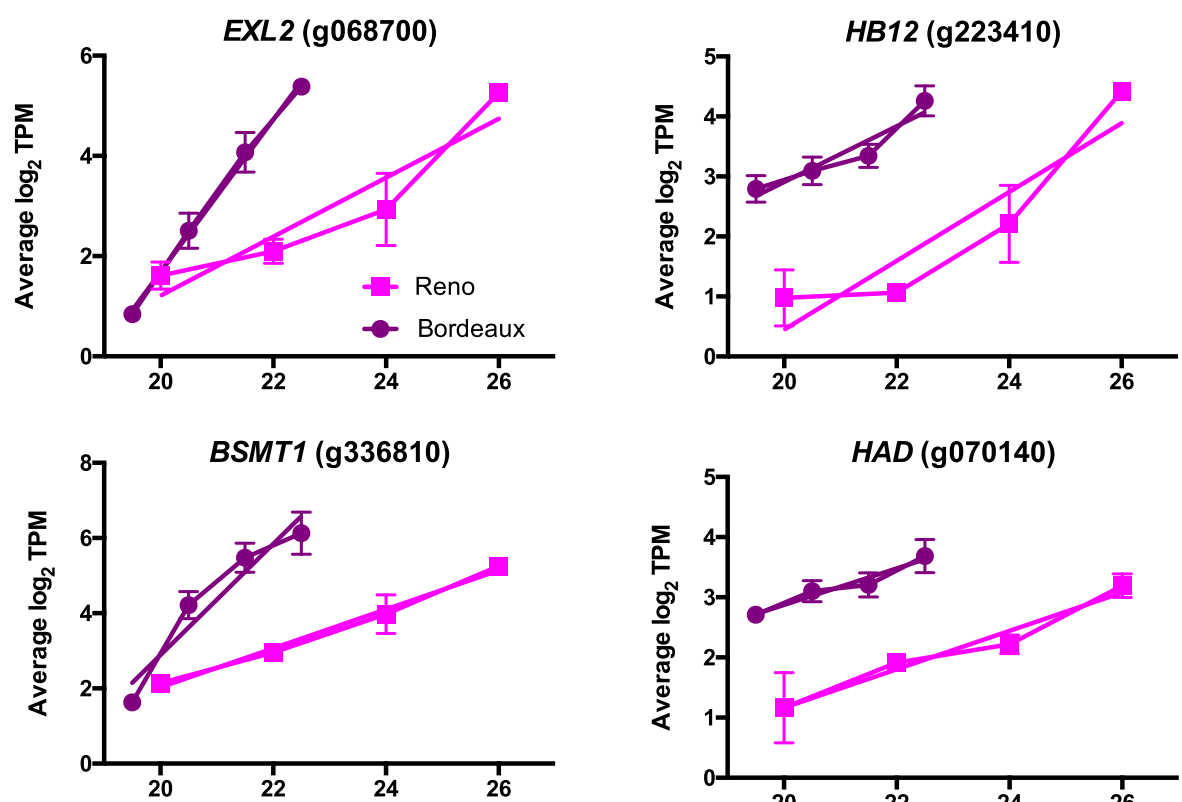

$H A D(g 070140)$
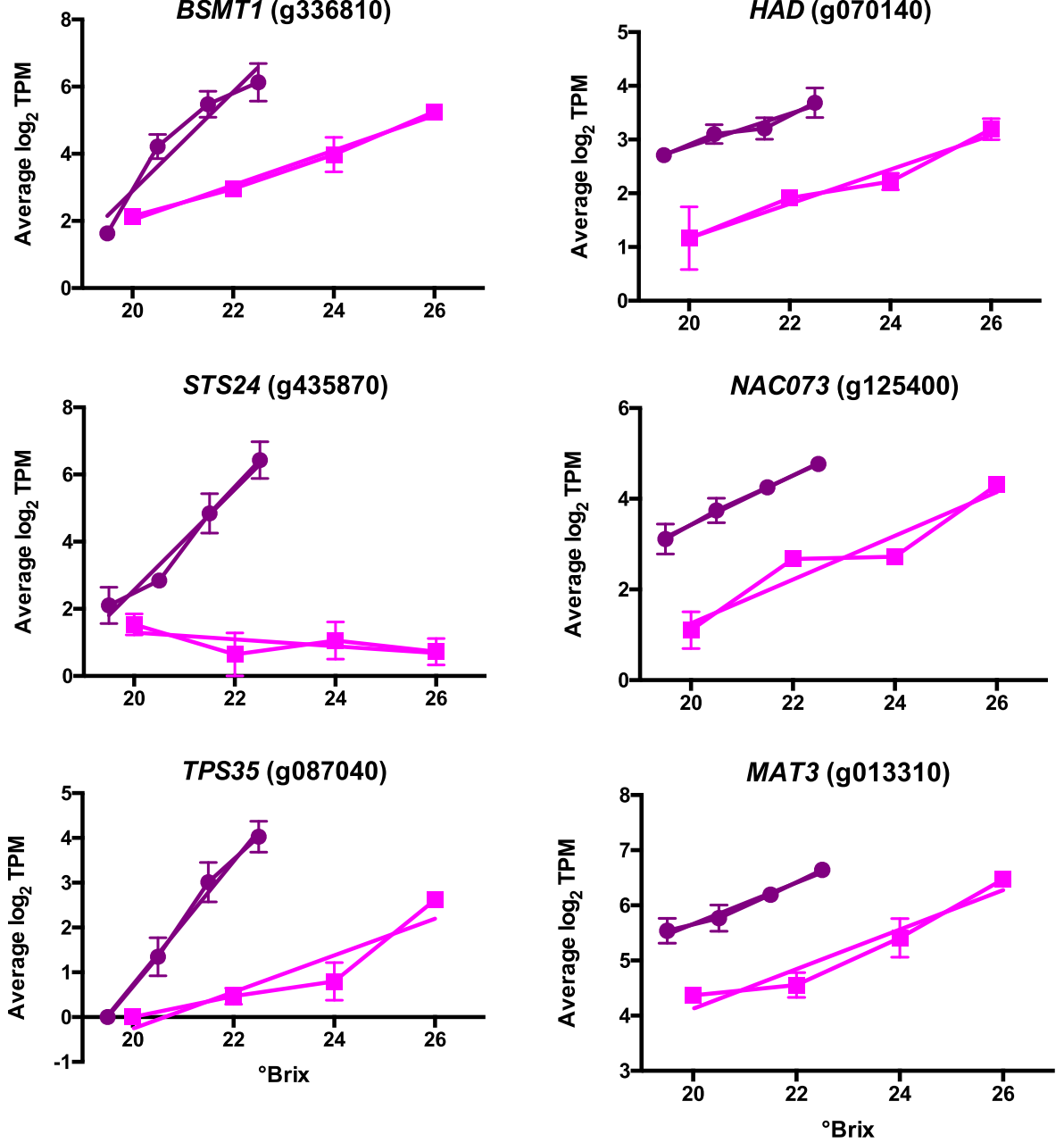

Fig. 2 Plots of the top genes from berry skins from Bordeaux and Reno with the highest increase in transcript abundance (TPM) between the lowest and highest sugar levels ('Brix). Values are the means $\pm \mathrm{SE}(n=3)$. Error bars not shown are smaller than the symbol. The symbol legend is displayed in the figure. EXL2 is EXordium Like 2; HB12 is HOMEOBOX 12; BSMT1 is a benzoate/salicylate methyltransferase 1; HAD is haloacid dehalogenase-like hydrolase protein; STS24 is stilbene synthase 24, NAC073 is a NAC domain containing protein; TPS 35 is terpene synthase 35 , and MAT3 is methionine adenosyltransferase 3

(Additional file 9); defense responses, response to fungus and response to ethylene stimulus were other highly enriched categories. The top 400 DEGs for RNO berries were enriched in response to oxygen-containing compound, response to hormone and response to abscisic acid (Additional file 10).

\section{DEGs with largest decreases in transcript abundance} between sugar levels

Eight examples of DEGs with the greatest decrease in transcript abundance with increasing sugar levels are presented in Fig. 3. They include lipid and cell wall proteins (e.g. extensin like and lipid transferase proteins) 


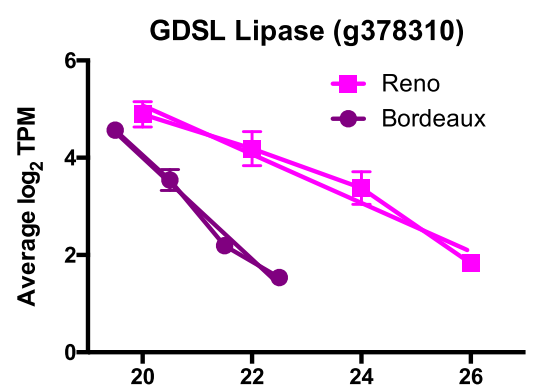

Bifunctional inhibitor lipid-transfer (g328890)
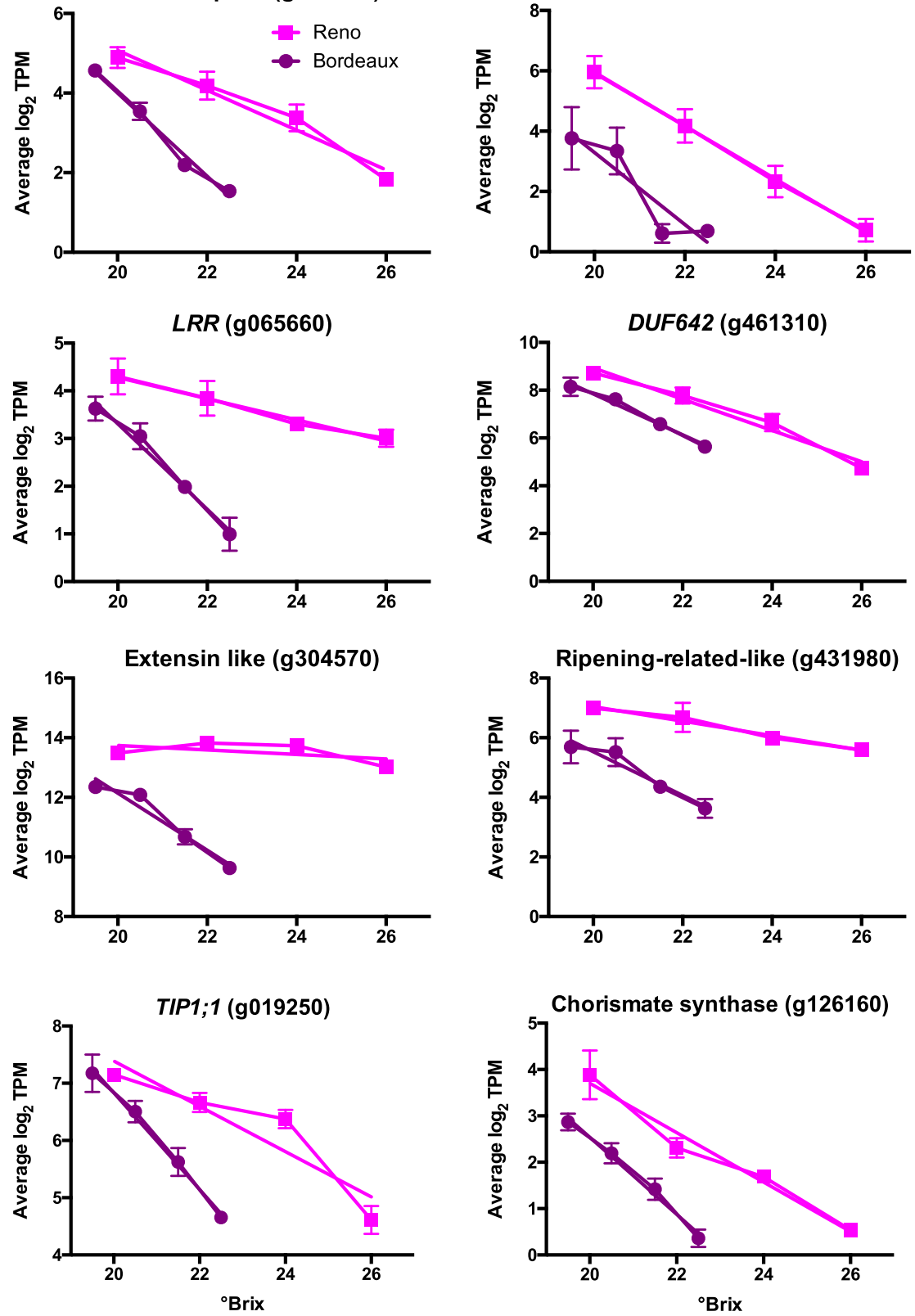

Fig. 3 Plots of the top genes from berry skins from Bordeaux and Reno with the highest decrease in transcript abundance (TPM) between the lowest and highest sugar levels ( $\left.{ }^{\circ} \mathrm{Brix}\right)$. Values are the means \pm SE $(n=3)$. Error bars not shown are smaller than the symbol. The symbol legend is displayed in the figure. GDSL is a sequence motif; LRR is a leucine rich repeat protein; DUF642 is a domain of unknown function protein; TIP1;1 is a tonoplast intrinsic protein 1;1

and an aquaporin (TIP1;1, tonoplast intrinsic protein 1; 1). The data were fitted to linear regressions and the slopes statistically compared between BOD and RNO berries. In some cases, the slopes of the linear regression lines of the DEGs were not statistically different (bifunctional inhibitor lipid transfer protein and DUF642 (domain of unknown function 642); but in the other cases presented, there were similar amounts of transcript abundance around $20^{\circ} \mathrm{Brix}$, but there were significantly different slopes. Again, there is a trend for the transcript abundance of many of these genes to change more significantly in BOD berries than RNO berries relative to sugar level.

\section{Differences in autophagy genes between BOD and RNO}

Berry ripening involves autophagy [4]. Generally, there was an increase in the transcript abundance of genes involved in autophagy as sugar level increased and the 
transcript abundance in BOD berries was higher relative to RNO berries at the same sugar level (Fig. 4). These trends are consistent with the hypothesis that BOD berries ripened faster than $\mathrm{RNO}$ berries relative to sugar level.

\section{Aroma- and flavor-associated DEGs}

Many aroma and flavor-associated compounds are synthesized in the late stages of berry ripening and sensitive to the environment. The major metabolic pathways affecting flavor and aromas in grapes and wines include the terpenoid, carotenoid, amino acid, and phenylpropanoid pathways [6]. These pathways were identified by topGO to be highly enriched in the DEGs and the turquoise module. Some of the DEGs are involved in these pathways and will be presented in the following subsections.

\section{Terpene synthase genes with the greatest transcript} abundance differences between BOD and RNO

Cultivar differences in berries are often ascribed to differences in aroma compounds. One of the main classes of cultivar specific aroma compounds is the terpene group [29]. The transcript abundance of a number of terpene synthases were higher in BOD berries as compared to RNO berries (Fig. 5). All but one of these (terpene synthase 55 ; TPS55) increased in transcript abundance with increasing sugar levels. TPS35 is a $\beta$ ocimine synthase ( $\beta$-ocimine is a main component of snapdragon flower aroma [30]). TPS08 is a $\gamma$-cadinene synthase, TPS26 is a cubebol $/ \delta$-cadinene synthase, TPS4 and 10 are (E)- $\alpha$-bergamotene synthases, and TPS07 and 28 are germacrene-D synthases; these enzymes produce sesquiterpenes found in essential plant oils (see [29] and references therein for the function of all of these terpenoid genes). TPS55 is a linalool/nerolidol synthase which synthesizes acyclic terpene alcohols; linalool contributes significantly to the floral aromas of grape berries and wines. TPS68 is a copalyl diphosphate synthase involved in diterpenoid biosynthesis and TPS69 is an ent-kaurene synthase. Both TPS68 and 69 are diterpene synthases and are part of the ent-kaurene biosynthesis pathway.

\section{Other terpenoid and carotenoid metabolism-related genes}

Carotenoid metabolism is another biosynthetic pathway that contributes to flavor and aroma in grapes [31]. There are a number of key genes that contribute to terpenoid and carotenoid metabolism that have a higher transcript abundance (Additional file 2) in BOD berries as compared to RNO berries. For example, DXR (1-deoxy-D-xylulose 5-phosphate reductoisomerase, g360850) catalyzes the first committed step and HDS (4-hydroxy3-methylbut-2-en-1-yl diphosphate synthase; g379980) enzyme controls the penultimate steps of the biosynthesis of isopentenyl diphosphate (IPP) and dimethylallyl diphosphate (DMAPP) via the methylerythritol 4phosphate (MEP) pathway. Other examples are two phytoene synthases (PSY), g180070 and g493850); PSY is the rate-limiting enzyme in the carotenoid biosynthetic pathway.
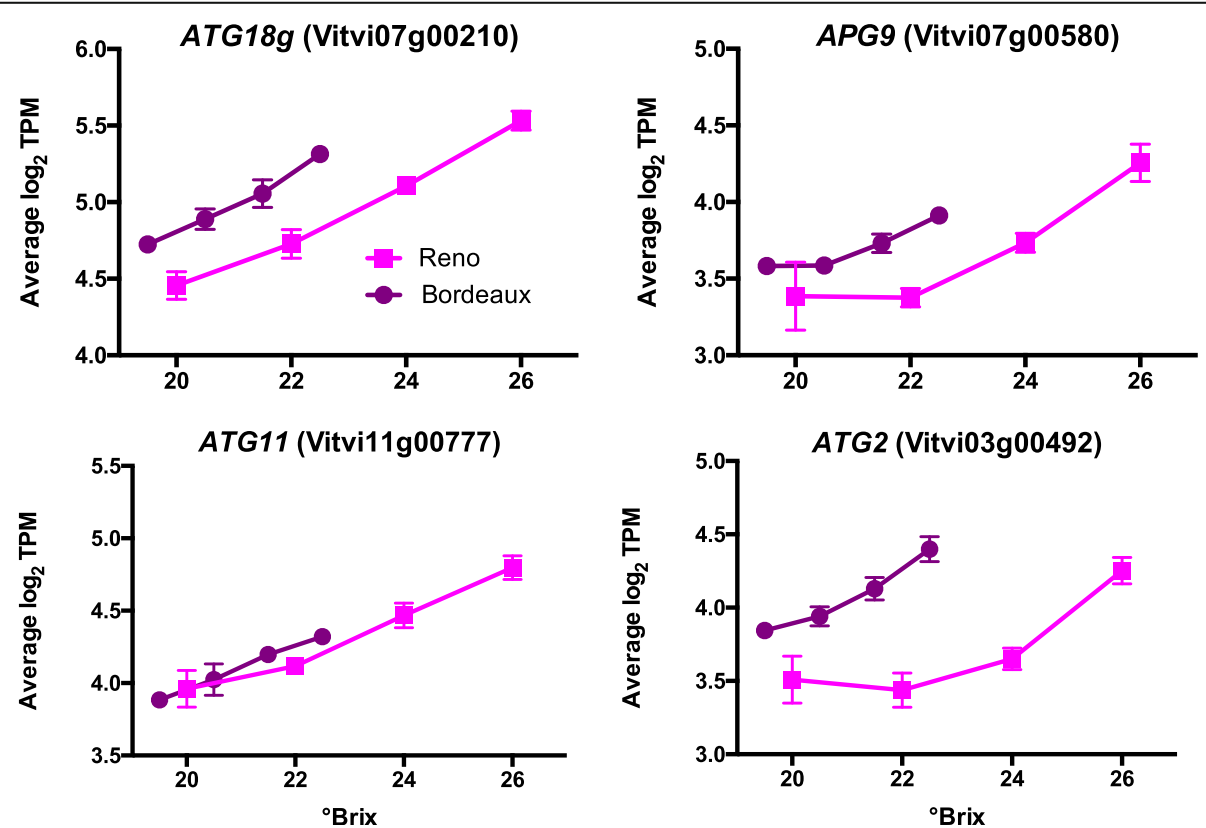

Fig. 4 The transcript abundance of some autophagy-related (ATG) genes. Data shown are the means $\pm \mathrm{SE} ; n=3$. Error bars not shown are smaller than the symbol. The symbol legend is displayed in the figure. APG9 is Autophagy 9 

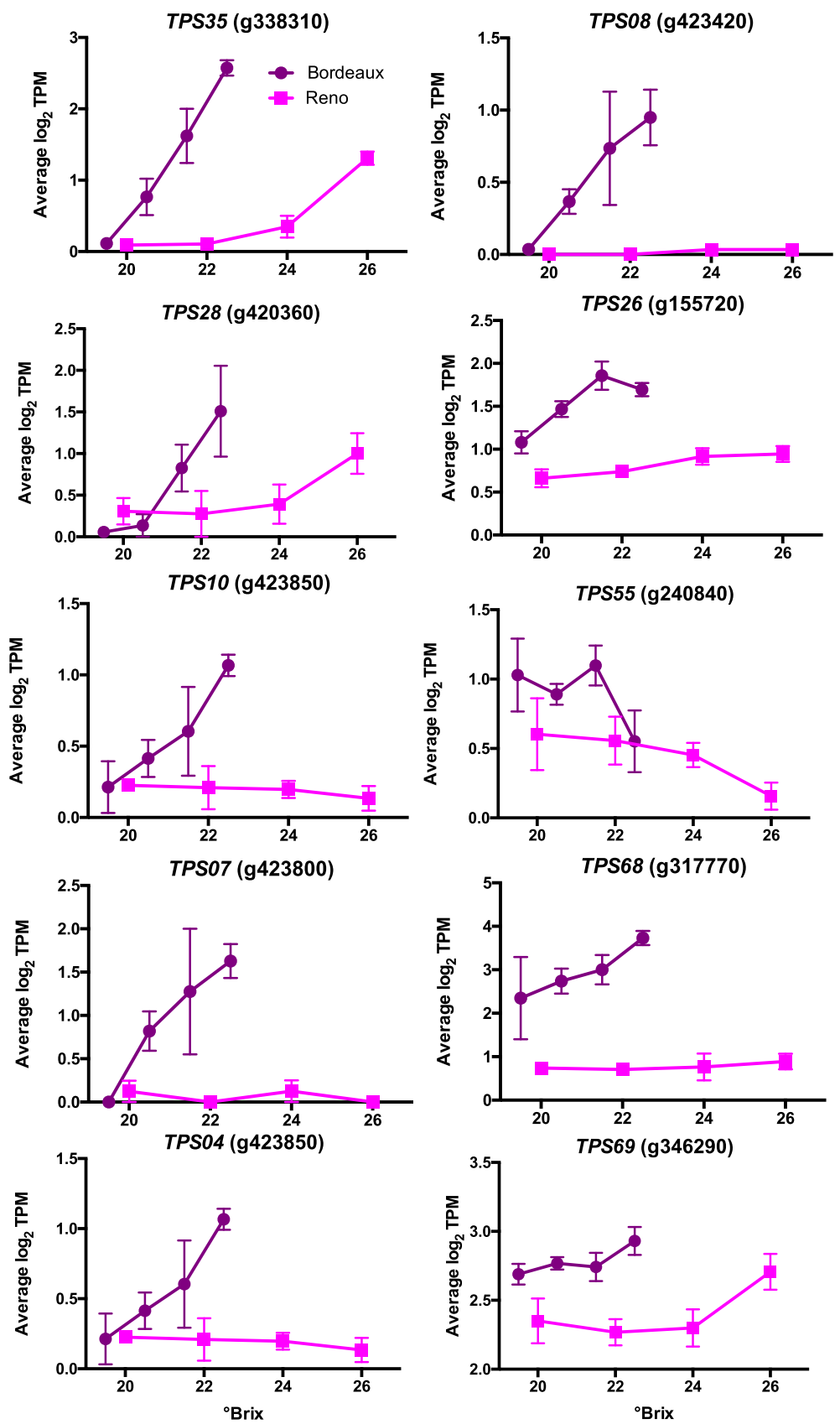

Fig. 5 Expression profiles of some terpene synthase (TPS) genes. Data shown are the means $\pm \mathrm{SE} ; n=3$. Error bars not shown are smaller than the symbol. The symbol legend is displayed in the figure

\section{Amino acid and phenylpropanoid metabolism genes}

Amino acids contribute to the aroma and flavor of grapes and wines [7]. The amino acid metabolism functional GO category is highly enriched in the group of DEGs between BOD and RNO (Additional file 3) and more specifically in the top 400 BOD DEGs (Additional file 9). Some examples of genes involved in amino acid metabolism that have a higher transcript abundance in BOD berries (see Fig. 6) are phenylalanine ammonia lyase 1 (PAL1, g533070 and eight other paralogs can be found in Additional file 2), which catalyzes the first step in phenylpropanoid biosynthesis, branched-chainamino-acid aminotransferase 5 (BCAT5, g220210), which is involved in isoleucine, leucine and valine biosynthesis, 3-deoxy-D-arabino-heptulosonate 7-phosphate synthase 1 (DHS1, g082490), which catalyzes the first committed step in aromatic amino acid biosynthesis), and tyrosine aminotransferase 7 (TAT7; g116950), which 

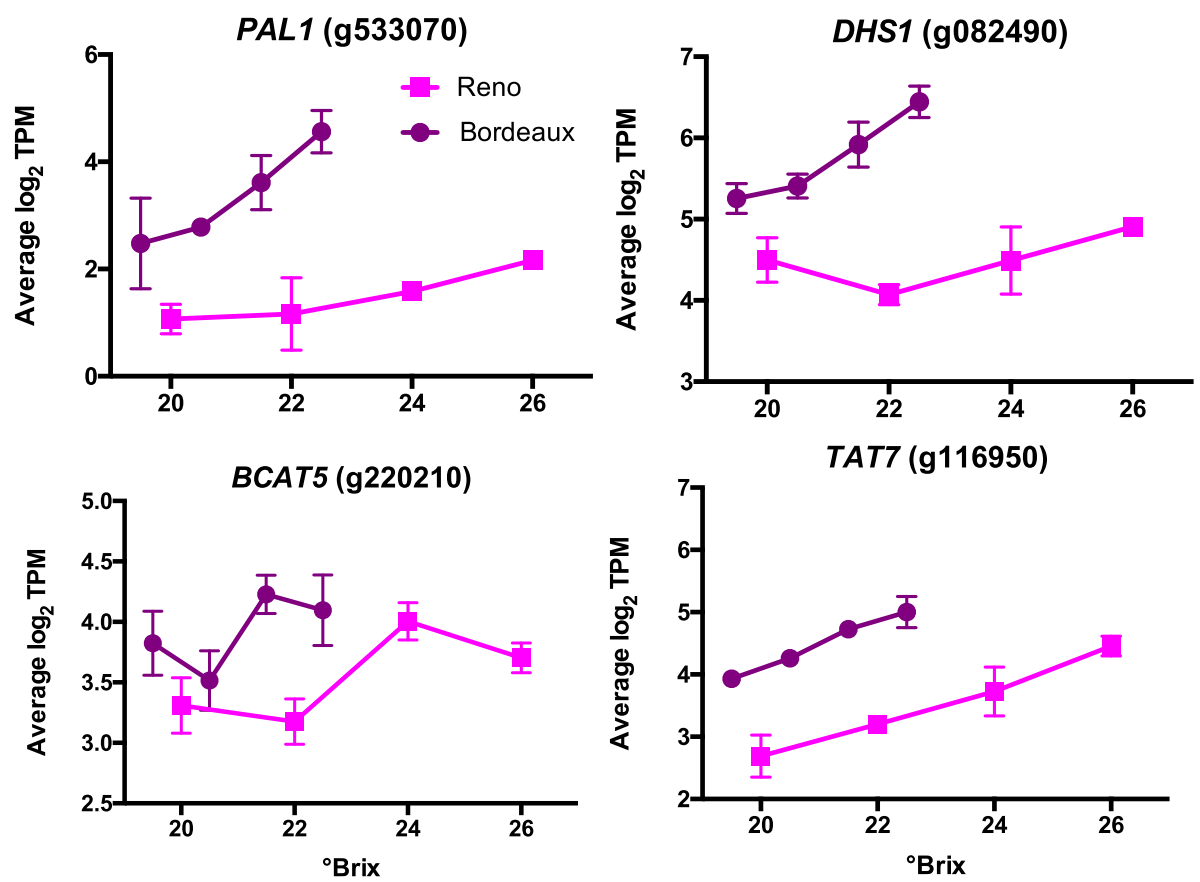

Fig. 6 The transcript abundance of some DEGs that are involved in the amino acid metabolism. Data shown are the means $\pm S E ; n=3$. Error bars not shown are smaller than the symbol. The symbol legend is displayed in the figure. PAL1 is a phenylalanine ammonia lyase; DHS1 is a 3-deoxyD-arabino-heptulosonate 7-phosphate synthase; BCAT5 is a branched-chain-amino-acid aminotransferase; and TAT7 is a tyrosine aminotransferase

is involved in tyrosine and phenylalanine metabolism. Included in this group were 44 stilbene synthases (STS), which are part of the phenylpropanoid pathway; these STSs had a higher transcript abundance in BOD berries as compared to RNO berries, with very similar transcript abundance profiles to $P A L 1$ (see Additional file 11 for two typical examples).

\section{DEGs associated with abiotic stimuli Light-responsive genes}

In a previous analysis, WGCNA defined a circadian clock subnetwork that was highly connected to transcript abundance profiles in late ripening grapevine berries [4]. To compare the response of the circadian clock in the two different locations, we plotted all of the genes of the model made earlier [4]. Most core clock genes (Additional file 12) and light sensing and peripheral clock genes (Additional file 13) had significantly different transcript abundance in BOD berries than that in RNO berries at the same sugar level (profiles bracketed in a red box). All but one of these (PHYC, phytochrome $C$, g088040) had higher transcript abundance in BOD berries relative to RNO berries. The transcript abundance of other genes had nearly identical profiles (not bracketed in a red box). These data are summarized in a simplified clock model (Fig. 7), which integrates PHYB as a key photoreceptor and temperature sensor [32, 33] that can regulate the entrainment and rhythmicity of the core circadian clock, although to be clear it is the protein activity of PHYB, not the transcript abundance that is regulating the clock.

\section{Chilling-responsive genes}

Temperatures were colder in RNO than BOD, reaching chilling temperatures in the early morning hours. A number of previously identified chilling-responsive genes [34] in Cabernet Sauvignon had a higher transcript abundance in $\mathrm{RNO}$ berries as compared to BOD berries (Fig. 8). These genes included CBF1 (C-repeat/DRE binding factor 1, g435450; previously named $C B F 4$, but renamed to be consistent with the ortholog of Arabidopsis), a transcription factor that regulates the cold stress regulon [35], IDD14 (Indeterminate-Domain 14, g000790), a transcription factor that generates an inhibitor to regulate starch metabolism [36], CML41 (calmodulin-like 41, g041290), that encodes a calmodulin-like protein, CYSB (cystatin B, g023260), a cysteine proteinase inhibitor that confers cold tolerance when overexpressed [37], XTH23 (xyloglucan endotransglucosylase/hydrolase 23, g572510), that encodes a cell wall loosening enzyme, and SULTR3;4 (sulfate transporter 3;4, g392710).

\section{DEGs associated with biotic stimuli}

The top DEGs in berries from BOD were highly enriched in the GO category for biotic stimuli including genes encoding pathogenesis proteins $(P R)$. The transcript abundance of 


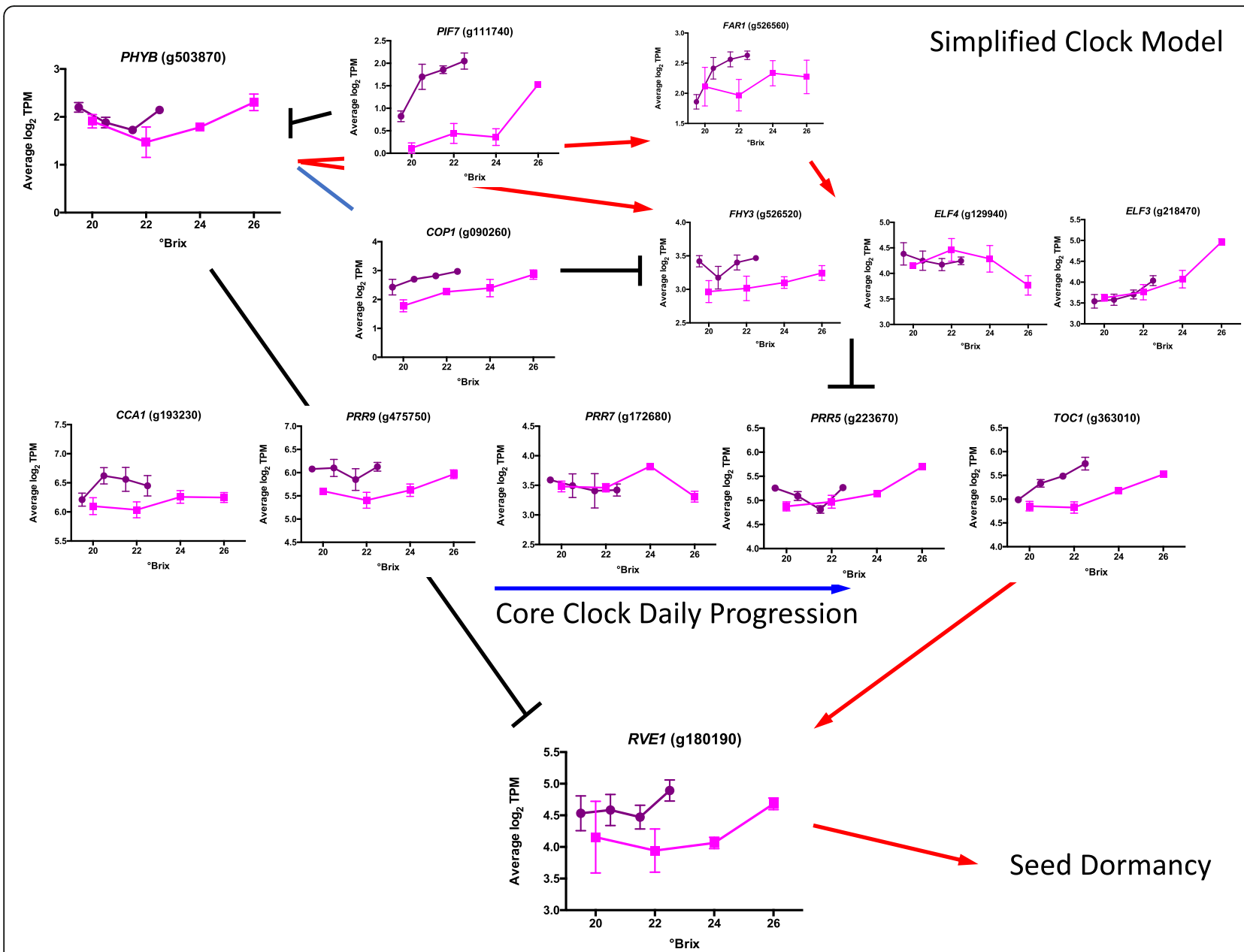

Fig. 7 A simplified model of the core circadian clock genes. Black lines and bars represent known inhibitory reactions, red arrows indicate known stimulatory reactions, and blue lines represent known physical interactions. PHYB is phytochrome B; PIF7 is Phytochrome Interacting Factor 7; COP1 is Constitutive Photomorphogenic 1; FAR1 is Far-Red Impaired Response 1; FHY3 is Far Red Elongated Hypocotyl 3; ELF4 is Early Flowering 4; ELF3 is Early Flowering 3; CCA1 is Circadian Clock Associated 1; PRR9 is Psuedo-Response Related 9; PRR7 is Psuedo-Response Related 7; PRR5 is Psuedo-Response Related 5; TOC1 is Timing of CAB expression 1; and RVE1 is Reveille 1

such genes in BOD berry skins was higher than those in RNO berries (Fig. 9). The transcript abundance of PR10 (g212910) increased with increasing sugar level. This gene responds in Cabernet Sauvignon leaves when infected with powdery mildew (Erysiphe necator) [38]. Powdery mildew induced other genes such as a PR3 protein (a class IV chitinase), a PR5 protein (thaumatin-like) and many stilbene synthases (see the phenylpropanoid metabolism section above and Additional file 11). The expression of these genes was also at much higher transcript abundance levels in BOD berries than in RNO berries. MLA10 (Intracellular Mildew A 10, g343420; Affymetrix probe set 1615715_at in [38]) matches to a fungal protein from $E$. necator. In that study, it was used as a control probe set to detect the presence of powdery mildew [38]. There was a higher transcript abundance of g343420 in BOD berries than that in RNO berries. These results indicate that there may have been a higher powdery mildew infection in BOD berries along with a higher induction of the phenylpropanoid pathway.

\section{DEGs associated with hormonal stimuli \\ Auxin signaling genes}

Auxin transport (38 genes; padj-value $=4.43 \mathrm{E}-08$ ) and cellular response to auxin stimulus (45 genes, padjvalue $=9.12 \mathrm{E}-05)$ were highly enriched GO categories for the DEGs (Additional file 3). Auxin is known to have multiple effects on grape berry ripening $[39,40]$. Auxin can delay berry ripening at the veraison stage, which is at the beginning of berry ripening. Some auxin metabolism (GH3.1; GH3 family protein, g538930) and signaling genes such as IAA13 (indole acetic acid 13, g527400), IAA27 (g326620), and ARF5 (auxin-response factor, g075570) had a higher transcript abundance in RNO berries (Additional file 1). Other auxin metabolism 

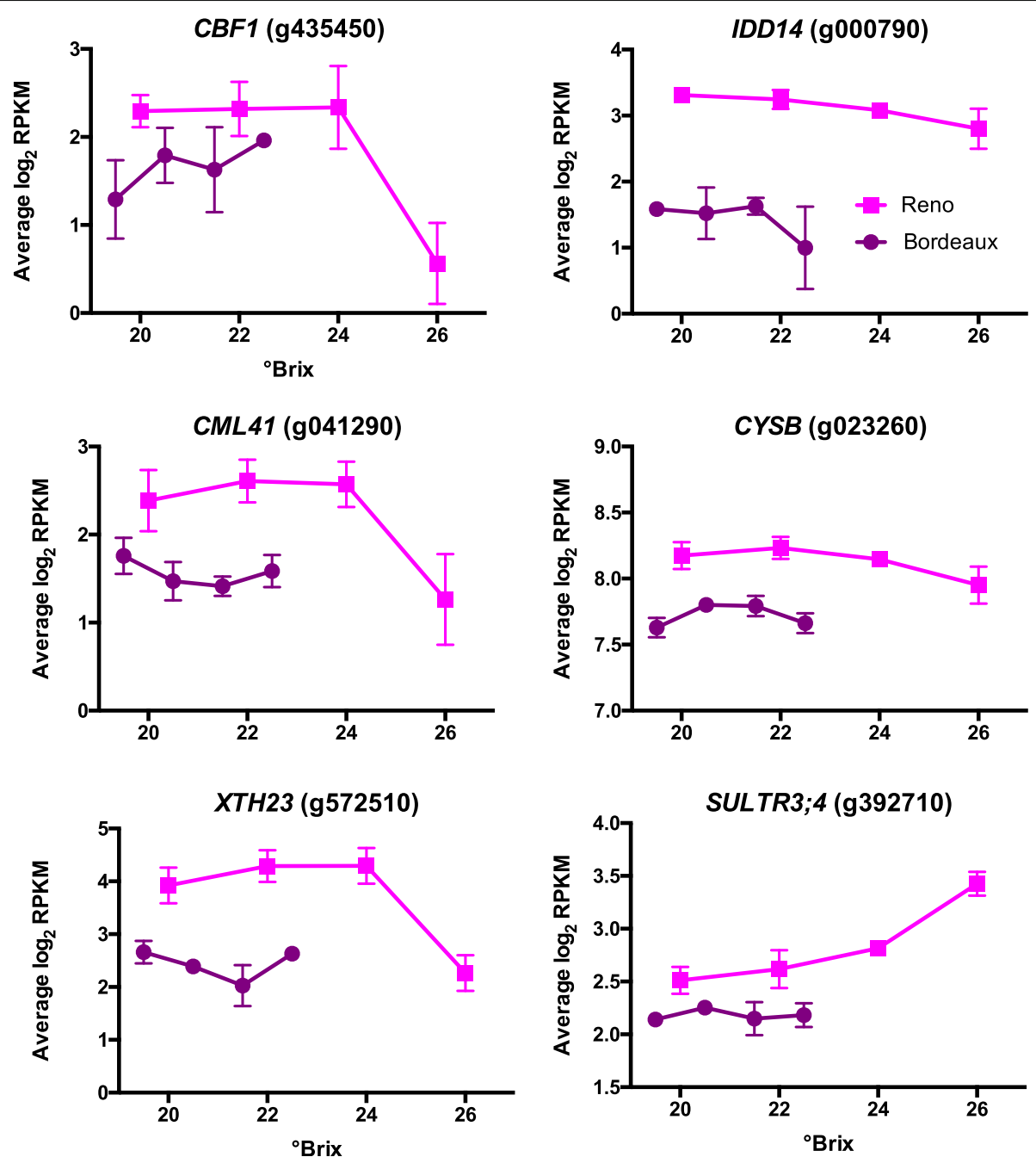

Fig. 8 Transcript profiles of some cold responsive genes. Data shown are the means $\pm S E ; n=3$. Error bars not shown are smaller than the symbol. The symbol legend is displayed in the figure. CBF1 is C-Repeat Binding Factor 1; IDD14 is Indeterminate-Domain 14; CML41 is Calmodulin 41; CYSB is Cystatin B; XTH23 is Xyloglucan Endotransglucosylase/Hydrolase 23 and SUFTR3;4 is Sulfate Transporter 3;4

(GH3.6, JAR1 (jasmonate resistant 1), g170030) and auxin signaling genes had a higher transcript abundance in BOD including ARF2 (g469780), ARF8 (g180460), ARF11 (g380160), IAA16 (g318830), ARAC1 (Arabidopsis RAC-like 1, g320970), and GID1B (gibberellic acid insensitive dwarf1B, g071190), a gibberellin receptor (Additional file 1).

\section{$A B A$ metabolism and signaling genes}

$\mathrm{ABA}$ is a stress hormone that responds to water deficits in grapevine [41]. A number of ABA-related genes are differentially expressed in berry skins between the two locations (Additional file 14). NCED3 (nine-cis epoxycarotenoid dioxygenase 3, g221190) and NCED5 (g404590), which are responsive to water deficit [42, 43], had higher transcript abundance in RNO and NCED6 (g203160), which is highly expressed in embryos [42], had higher transcript abundance in BOD. NCED6, but not NCED3 is involved in seed ABA and seed dormancy [43]. Additionally a number of other genes involved in the $A B A$ signaling pathway had higher transcript abundance in BOD including $A B F 2$ (abscisic acid responsive elements binding factor 2, g286950), ABF4 (g312300) and ABCG40 (adenosine triphosphate binding casette $\mathrm{G} 40$, g143240) [44, 45]. Interestingly, BAM1 (Barley Any Meristem 1) was identified to be the receptor to a root signaling peptide hormone (CLE25, clavata3/esr-related 25) that responds to water deficit and upregulates NCED3 transcript abundance in Arabidopsis leaves [46]. The transcript abundance of BAM1 (g220020) was significantly higher in RNO berries than that of BOD berries (Additional file 14). There were no significant differences in the transcript abundance of CLE25 (g007470); it was highly variable. 

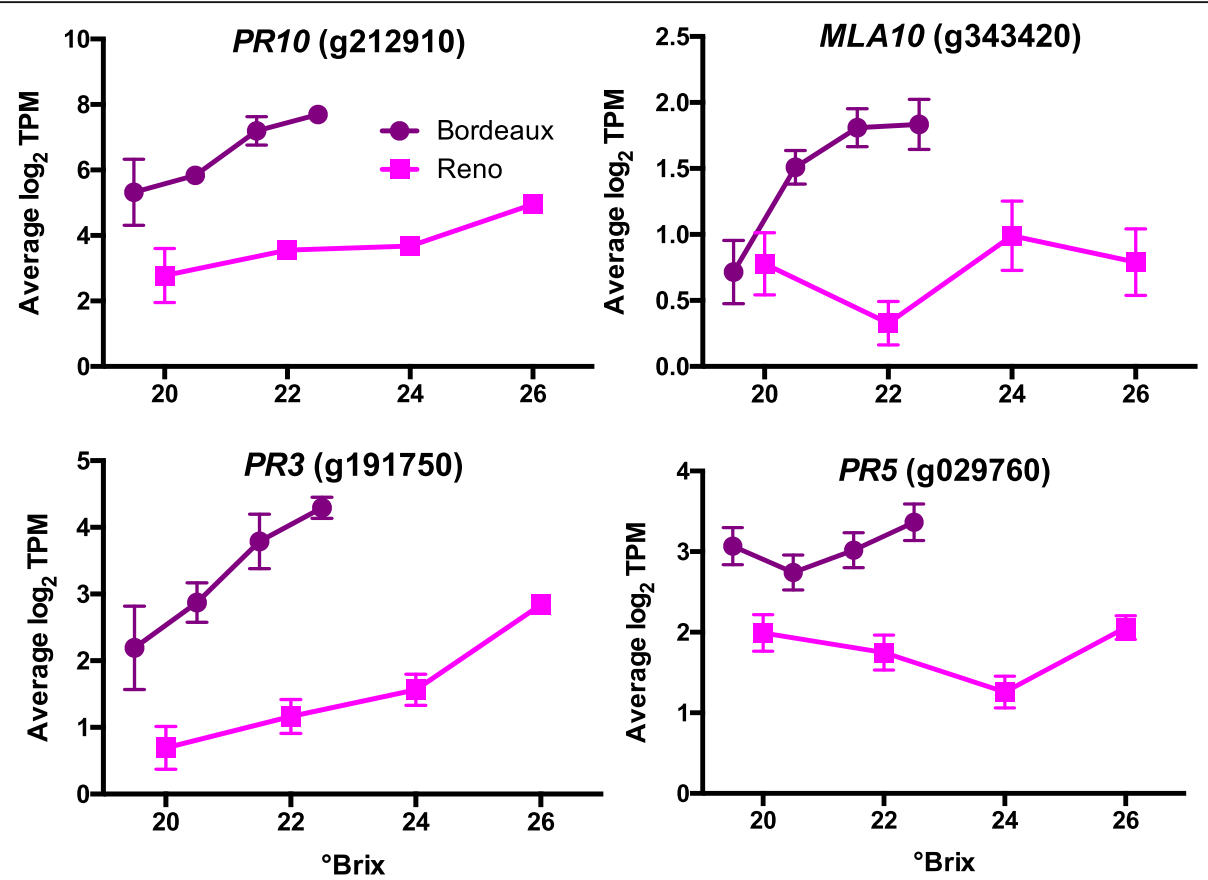

Fig. 9 Expression profiles of pathogenesis proteins (PR) involved with powdery mildew. Data shown are the means $\pm S E ; n=3$. Error bars not shown are smaller than the symbol. The symbol legend is displayed in the figure. MLA10 is Intracellular Mildew A 10

\section{Ethylene signaling genes higher in BOD}

There were 71 DEGs that were enriched in the response to ethylene GO category (Additional file 3). Ethylene is a stress hormone that responds to many types of biotic [47] and abiotic [48] stresses in addition to its role in fruit development and ripening [49]. Many ethylenerelated genes had a higher transcript abundance in BOD berries. These included ethylene biosynthesis, ethylene receptors and ERF (ethylene response factor) transcription factors (Fig. 10). ERF1 and ERF2 are at the beginning of the ethylene signaling pathway and are direct targets of EIN3 $[45,50]$. Other ERF transcription factors (e.g. ERF98; g156210) identified as hubs in the ethylene signaling pathway in Arabidopsis leaves [51] were also differentially expressed in a similar manner as ERF1 (g060690) and ERF2 (g482650) between the two locations (data not shown).

\section{DEGs associated with mineral nutrients Iron-related genes}

Fourteen DEGs were associated with genes enriched in response to iron ion (Additional file 3); Eight examples of DEGs involved in iron homeostasis are shown in Fig. 11. Iron homeostasis genes SIA1 (salt-induced ABC kinase, g336700), VIT1 (vacuolar iron transporter 1, g001160), ATH13 (Arabidopsis thaliana ABC2 homolog 13, g146610), IREG3 (iron regulated 3, g098530), and ABCI8 (ATP-binding cassette I8, g163790) have higher transcript abundance in BOD berries than in $\mathrm{RNO}$ berries. Iron homeostasis genes YSL3 (yellow stripe-like 3, g223320), FER1 (ferritin 1, g606560), and NRAMP3 (natural resistance-associated macrophage protein 3, g413920) had higher transcript abundance in RNO berries compared to BOD berries. Several other ferritin genes were expressed similarly to FER1 (data not shown). Average available iron soil concentrations were about 5 times higher in the BOD vineyard soil compared to the RNO vineyard soil (Table 1).

\section{Discussion}

The common gene set (ap2-ap1_union_ap3-ap1) for both locations represented approximately $25 \%$ of the genes differentially expressed with sugar level or location. Presumably these gene sets represent genes that were not influenced by location (environment) but were influenced by berry development or sugar level. This study is limited in that only two locations in one season were investigated. As more locations are compared in the future, these gene sets will likely be reduced in size even further. The processes involved in these gene sets or modules included the increase of catabolism and the decline of translation and photosynthesis. It is clear that these processes play important roles in berry ripening. Most of the genes in the genome varied in transcript abundance with increasing sugar levels and berry maturation and most of these varied with the vineyard site. Many of the DEGs were enriched with gene ontologies associated with environmental or hormonal stimuli. 

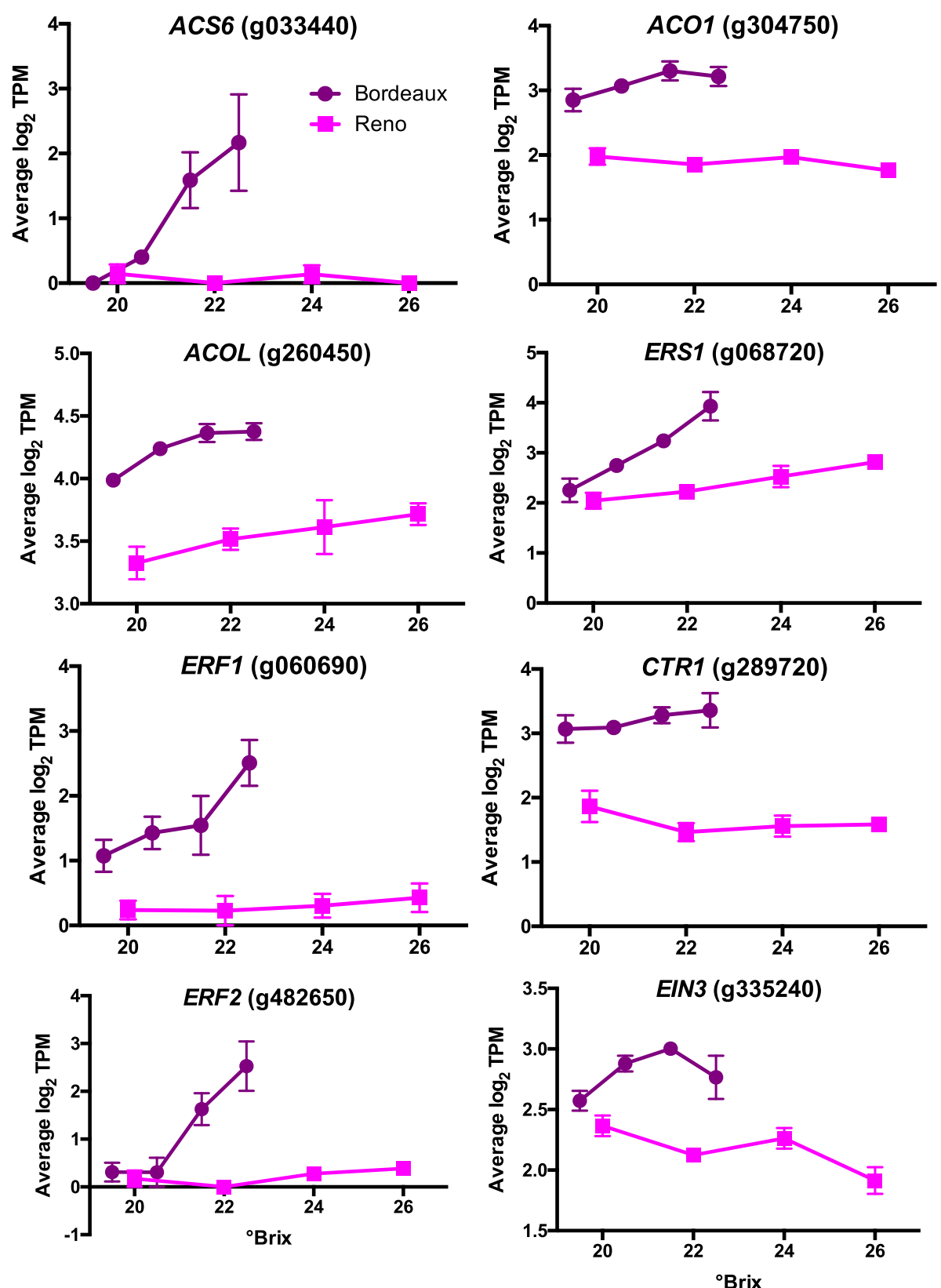

Fig. 10 The transcript abundance of DEGs involved with ethylene metabolism and signaling. Data shown are the means $\pm S E ; n=3$. Error bars not shown are smaller than the symbol. The symbol legend is displayed in the figure. ACS6 is 1-Aminocyclopropane-1-Carboxylic Acid (ACC) Synthase 6; ACO1 is ACc Oxidase 1; ACOL is ACc Oxidase-Like; ERS1 is Ethylene Response Sensor 1; CTR1 is Constitutive Triple Response 1, EIN3 is Ethylene-Insenstive 3; and ERF1 and ERF2 are Ethylene Response Factors 1 and 2

DEG expression profiles of grape berry skins were associated with environmental factors and seed development

Plants are exposed to a multitude of factors that influence their physiology even in controlled agricultural fields such as vineyards. The vineyards in BOD and RNO are exposed to very different environments (including climate); these environmental influences were reflected in some of the DEG sets with enriched gene ontologies. The results from this study are consistent with the hypothesis that the transcript abundance of berry skins in the late stages of berry ripening were sensitive to local environmental influences on the grapevine.

While most transcript abundances in berries are largely influenced by genetics or genotype, environment also plays a large role [2]. It is impossible with the experimental design of this study to determine the amount 

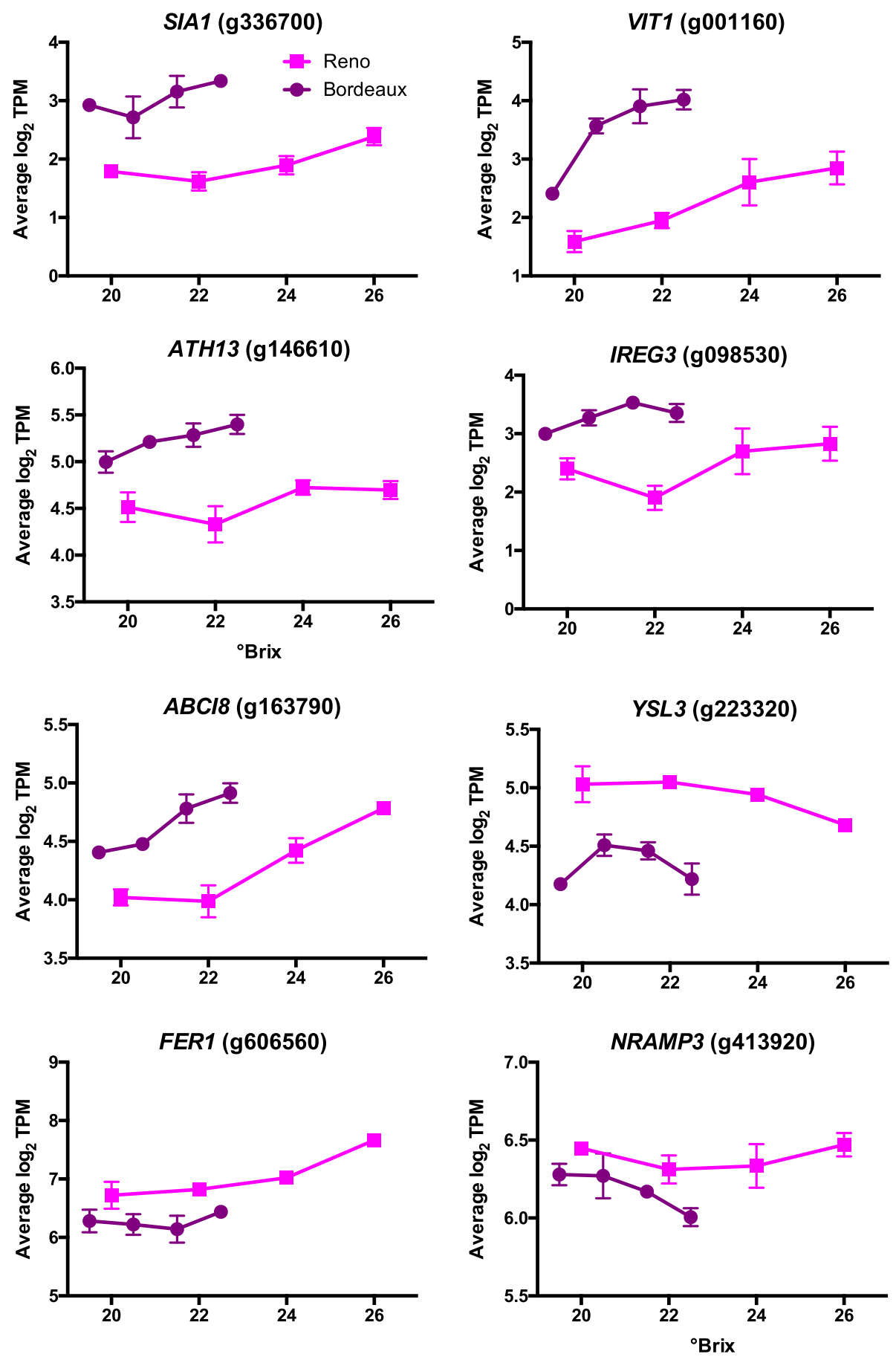

Fig. 11 Expression profiles of DEGs involved in iron homeostasis. Data shown are the means $\pm S E ; n=3$. Error bars not shown are smaller than the symbol. The symbol legend is displayed in the figure. SIA1 is Salt-Induced ABC1 Kinase 1; VIT1 is Vacuolar Iron Transporter 1; FER1 and 2 are Ferritin 1 and 2; YSL3 is Yellow Stripe-like 3; IREG3 is Iron-Regulated Protein 3; NRAMP3 is Natural Resistance-Associated Macrophage Protein 3; ATH13 is ABC2 homolog 13; and ABCl8 is ATP-Binding Cassette 18

that each of the environmental factors contributed to the amount of differential expression in these two locations. There were too many variables and too many potential interactions to determine anything conclusively. Replication in other seasons will not aid this analysis as climate is highly variable and will produce different results. All we can say is that these genes were differentially expressed between the two locations, which were likely due to known and unknown factors (a sense of place or terroir). As additional studies are conducted in 
different locations and seasons in the future, metaanalyses can be employed to provide firmer conclusions.

It is possible that some of the DEGs identified in this study resulted from genetic differences between the different Cabernet Sauvignon clones and rootstock used in the two locations. Not knowing what these genes might be from previous studies prevents us from drawing any clues. These and other factors most certainly affected the berries to some degree. The data in this study indicated that the grape berry skins responded to multiple potential environmental factors in the two vineyard locations in addition to potential signals coming from the maturing seed. We say potential environmental factors because we did not control for these factors; we associated transcript abundance with the factors that were different in the two locations. The transcript abundance profiles along with functional annotation of the genes gave us clues to factors that were influencing the berries and then associations were made with the known environmental variables. Further experiments are required to follow up on these observations.

We were able to associate differences in transcript abundance (DEGs) between the two locations. These DEGs could be associated with temperature, light, moisture, and biotic stress. Additional factors were associated with transcript abundance involved with physiological responses and berry traits such as seed and embryo development, hormone signaling (ABA, ethylene and auxin), phenylpropanoid metabolism, and the circadian clock. In the following sections we discuss in more detail some of the possible environmental factors that were reflected in the enriched gene ontologies found in the gene sets from this study.

\section{Transcript abundance of light-responsive genes}

Light regulates the transcript abundance of many genes in plants. It has been estimated that $20 \%$ of the plant transcriptome is regulated by white light and this includes genes from most metabolic pathways [52]. Light is sensed by a variety of photoreceptors in plants [33]; there are red/far red, blue and UV light receptors. PHYB is a key light sensor, regulating most of the light sensitive genes [53] and sensing the environment through red light to far-red light ratios and temperature [33, 54]. PHYB entrains the circadian clock affecting the rate of the daily cycle [55] and the expression of many the circadian clock genes [53]; PHYB induces morning phase genes and represses evening phase genes. Other photoreceptors can entrain the circadian clock as well [33].

PHYB and the circadian clock are central regulators of many aspects of plant development including seed germination, seedling growth, and flowering $[33,55,56]$. The circadian clock influences the daily transcript abundance of genes involved in photosynthesis, sugar transport and metabolism, biotic and abiotic stress, even iron homeostasis [55].

Light signaling was very dynamic in the berry skin transcriptome in the late stages of berry ripening with a higher transcript abundance of many light signaling genes in BOD berries. Many photoreceptors that interact with the circadian clock had a higher gene expression in BOD berries. In the circadian clock model, Circadian Clock Associated 1 (CCA1) is an early morning gene and has its highest expression at the beginning of the day. It is at the start of the circadian core clock progression through the day, whereas the transcript abundance of Timing Of CAB Expression 1 (TOC1) is highest at the end of the day and finishes the core clock progression (Fig. 7). In both of these cases, there is a higher transcript abundance of these genes in BOD than in RNO.

The evening complex is a multi-protein complex composed of Early Flowering 3 (ELF3), Early Flowering 4 (ELF4) and Phytoclock 1 (PCL1 also known as LUX) that peaks at dusk. None of these proteins, had significant differences in transcript abundance between the two locations (Fig. 7; Additional file 12). The transcript abundance of ELF3 increased with sugar level and shortening of the day length (the higher sugar level comes later in the season and thus is at a shorter day length). ELF3, as part of the evening complex (EC), has direct physical interactions with PHYB, COP1 (Constitutive Photomorphogenic 1) and TOC1 [57] linking light and temperature signaling pathways directly with the circadian clock. It is interesting that most of the components of the clock showed significant differences in transcript abundance between BOD and RNO, except for the three proteins that make up the evening clock.

The transcript abundance profile of $P H Y B$ was similar in both BOD and RNO berries (Fig. 7), however the changes in transcript abundance with sugar level occurred in BOD berries at a lower sugar level. There was a gradual decline of PHYB transcript abundance with increasing sugar level until the last measurement at the fully mature stage, where there was a large increase in transcript abundance. A very similar profile is observed for Reveille 1 (RVE1). RVE1 promotes seed dormancy in Arabidopsis and PHYB interacts with RVE1 by inhibiting its expression [58]. PIF7 (Phytochrome Interacting Factor 7), interacts directly with PHYB to suppress PHYB protein levels [59]. Likewise, PIF7 activity is regulated by the circadian clock [60]. PIF7 had higher transcript abundance in the BOD than that of RNO berries and generally increased with increasing sugar level. The transcript abundance of two of the other grape phytochromes (PHYA and PHYE) did not vary significantly between the two locations or at different sugar levels. $P H Y C$ had a higher transcript abundance in RNO berries and did not change much with different sugar levels. Many other light receptors (e.g. CRY3 (cryptochrome 3), FAR1 (far-red 
impaired response 1), FRS5 (FAR1-related sequence 5), etc.) had higher transcript abundance in BOD berries (Additional file 13). Thus, light sensing through the circadian clock is a complicated process with multiple inputs.

RVE1 follows a circadian rhythm [61]. It behaves like a morning-phased transcription factor and binds to the EE element, but it is not clear if it is affected directly by the core clock (e.g. TOC1 or EC which repress other morning gene paralogs like CCA1 and $L H Y$ (late elongated hypocotyl)) or through effects of PHYB or both. PHYB downregulates RVE1; RVE1 promotes auxin concentrations and decreases gibberellin (GA) concentrations [58]. Warmer night temperatures (as in BOD) cause more rapid reversion of the active form of PHYB to the inactive form [33] and thus may promote a higher expression/activity of RVE1. $\mathrm{P}_{\mathrm{r}}$ (phytochrome in the red form, which is the physiologically inactive form) appears to accelerate the pace of the clock [55]. It is unclear what role phytochromes might have in seed and fruit development in grapes.

Very little is known about the effect of PHY on fruit development in general. In one tomato study, the fruit development of phy mutants was accelerated [62], suggesting that $\mathrm{PHYB}$ as a temperature/light sensor and a regulator of the circadian clock may influence fruit development. Carotenoid concentrations, but not sugar concentrations, also were affected in these mutants.

Photoperiod affects the transcript abundance of PHYA and PHYB in grape leaves [63]. In the present study, the transcript abundance of the majority of the photoreceptor genes in berry skins, including red, blue and UV light photoreceptors, had a higher transcript abundance in BOD berries (Additional file 13). It is unclear what the effect of $\mathrm{PHYB}$ and the circadian clock have on grape berry development. However, there were clear differences between the two locations; it seems likely that PHYB and the circadian clock are key grape berry sensors of the environment, affecting fruit development and composition.

\section{Transcript abundance of temperature-responsive genes}

The grape berry transcriptome is sensitive to temperature [2,3]. Temperature related genes were differentially expressed at the two locations in our study. The RNO berries were exposed to a much larger temperature differential between day and night than BOD berries and were also exposed to chilling temperatures in the early morning hours during the late stages of berry ripening (Table 1). The transcript abundance of some cold-responsive genes was higher in RNO berry skins than in BOD berry skins (Fig. 8), including CBF1.

$C B F 1$ transcript abundance is very sensitive to chilling temperatures; it is a master regulator of the cold regulon and improves plant cold tolerance [35, 64, 65]. PIF7 binds to the promoter of $C B F 1$, inhibiting $C B F 1$ transcript abundance, linking phytochrome, the circadian clock and $C B F 1$ expression [60]. Our data are consistent with this model; transcript abundance of PIF7 was higher and CBF1 transcript abundance was lower in BOD berry skins than RNO berry skins (Fig. 7).

\section{Transcript abundance of dehydration and seed dormancy genes}

ABA concentrations in plants increase in response to dehydration and ABA triggers a major signaling pathway involved in osmotic stress responses and seed development [66]. ABA concentrations only increase in the seed embryo near the end of seed development when the embryo dehydrates and goes into dormancy. ABA concentrations remain high to inhibit seed germination. The transcript abundance of ABA signaling genes such as $A B F 2$ and $S n R K 2$ (SNF1 related protein kinase 2) kinases increase after application of ABA to cell culture [67] and in response to dehydration [45] in leaves of Cabernet Sauvignon.

The data in this study are consistent with the hypothesis that BOD berries are riper at lower sugar levels. The ABA signaling genes in the berry skins had higher transcript abundance in $\mathrm{BOD}$ berries indicating that $\mathrm{ABA}$ concentrations were higher in BOD than RNO berries even though RNO berries were exposed to drier conditions (Table 1). ABA concentrations may be higher in the BOD berry skins based upon the higher transcript abundance of important ABA signaling and biosynthesis genes encoding ABF2, SnRK2 kinases and NCED6. We hypothesize that this would be seed derived ABA since water deficits were not apparent in BOD with the recent rainfall and high humidity. In contrast, NCED3 and NCED5 had higher transcript abundance in RNO berry skins, which might occur as the result of the very low humidity and large vapor pressure deficit (the vines were irrigated). The lower expression of NCED6 in RNO berry skins may indicate that the seeds in the berry were more immature than the BOD berries. The higher expression of other seed development and dormancy genes (e.g. RVE1, ARF2, ARF10, etc.) in the berry skins support the argument that BOD berries (and seeds) matured at a lower sugar level than the RNO berries.

The ABA concentrations in the berry skins are a function of biosynthesis, catabolism, conjugation and transport. ABA in seeds increase as the seed matures and some of this ABA may be transported to the skin. In fact, a number of $A B C G 40$ genes, which encode $\mathrm{ABA}$ transporters, had higher transcript abundance in BOD berry skins than that in RNO (Additional file 2 and 14). Part of the ABA in skins may be transported from the seed and part of it might be derived from biosynthesis in the skins. NCED6 transcript abundance in the skins was 
higher in BOD berries. Perhaps the transcript abundance of NCED6 in the skin is regulated by the same signals as the embryo and reflects an increase in seed maturity. AtNCED6 transcript abundance is not responsive to water deficit in Arabidopsis, but AtNCED3 and AtNCED5 are [43]. This is consistent with the higher NCED3, NCED5 and BAM1 transcript abundance in RNO berries (Additional file 14). Thus, there are complex responses of $\mathrm{ABA}$ metabolism and signaling. It would appear that there may be two different ABA pathways affecting $\mathrm{ABA}$ concentrations and signaling: one involved with embryo development and one involved with the water status in the skins.

Auxin is also involved with ABA signaling during the late stages of embryo development in the seeds. Auxin signaling responses are complex. ABF5 is an auxin receptor that degrades Aux/IAA proteins, which are repressors of ARF transcriptional activity [68]. Thus, a rise in auxin concentration releases Aux/IAA repression of ARF transcription factors, activating auxin signaling. In the berry skins, there was a diversity of transcriptional responses of $A u x / I A A$ and $A R F$ genes in the two locations, some with increased transcript abundance and others with decreased transcript abundance. As with ABA signaling, there may be multiple auxin signaling pathways operating simultaneously.

One pathway appears to involve seed dormancy. ARF2 had a higher transcript abundance in BOD berries. ARF2 promotes dormancy through the ABA signaling pathway [69]. This is consistent with the hypothesis that BOD berries reach maturity at a lower sugar level than RNO berries.

\section{Transcript abundance of biotic stress genes}

Grapevines have very dynamic gene expression responses to pathogens [70, 71]. The top 150 DEGs for BOD berries were highly enriched with biotic stress genes. The BOD vineyard site had a higher rainfall and higher relative humidity than RNO and these conditions are likely to be more suitable for fungi to grow. We detected a much higher transcript abundance of powdery mildew-responsive genes in BOD berries and this may be connected to a higher transcript abundance of ethylene and phenylpropanoid genes as part of a defense response. The transcript abundance profiles of some of these genes (e.g. PR10, PAL1, STS10, ACS6, and ERF2; see Figs. 5, 8, 9 and Additional file 11) are remarkably similar.

Increased ethylene signaling in grapevines has been associated with powdery mildew infection and phenylpropanoid metabolism and appears to provide plant protection against the fungus [72, 73]. Genes involved with phenylpropanoid metabolism, especially PAL and STS genes, appear to be quite sensitive to multiple stresses in the environment [74]. In Arabidopsis there are four $P A L$ genes [75]. These $P A L$ genes appear to be involved with flavonoid biosynthesis and pathogen resistance in Arabidopsis. Ten different PAL1 and two PAL2 orthologs had higher transcript abundance in BOD berry skins; many STS genes also had a higher transcript abundance in BOD berry skins (Additional file 11). Stilbenes are phytoalexins and provide pathogen resistance in grapes and STS genes are strongly induced by pathogens [70]. Thus, the higher transcript abundance of powdery mildew genes may be associated with the higher transcript abundance of genes in the ethylene and phenylpropanoid pathways.

\section{Transcript abundance of iron homeostasis genes}

The transcript abundance of a number of iron homeostasis genes were significantly different in the two locations (Fig. 11) and there was a difference in soil available iron concentrations in the two locations. However, iron uptake and transport in plants is complicated depending on multiple factors, such as $\mathrm{pH}$, soil redox state, organic matter composition, solubility in the phloem, etc. Thus, it is impossible to predict iron concentrations in the berry without direct measurements. The roles of these genes in iron homeostasis and plant physiological functions are diverse. Iron supply can affect anthocyanin concentrations and the transcript abundance of genes in the phenylpropanoid pathway in Cabernet Sauvignon berry skins [76]. One of the DEGs, SIA1, is located in the chloroplast in Arabidopsis and appears to function in plastoglobule formation and iron homeostasis signaling in concert with ATH13 (also known as OSA1) [77]. Another DEG, YSL3, is involved in iron transport [78]. It acts in the SA signaling pathway and appears to be involved in defense responses to pathogens. It also functions in iron transport into seeds [79]. FER1 is one of a family of ferritins (iron-binding proteins) found in Arabidopsis [80]. VIT1 and NRAMP3 are vacuolar iron transporters [81] and are also involved in iron storage in seeds. Other DEGs are also responsive to iron supply. IREG3 (also known as MAR1) appears to be involved in iron transport in plastids; its transcript abundance increases with increasing iron concentrations [82]. ABCI8 is an iron-stimulated ATPase located in the chloroplast that functions in iron homeostasis [83].

It is unclear what specific roles these iron homeostasis genes are playing in grape berry skins, but they appear to be involved in iron storage in seeds and protection against oxidative stress responses $[80,81]$. One possible explanation for the transcript abundance profiles in the BOD and RNO berry skins is that ferritins are known to bind iron and are thought to reduce the free iron concentrations in the chloroplast, thus, reducing ROS production that is caused by the Fenton reaction [80]. As chloroplasts senesce during berry ripening, iron concentrations may 
rise as a result of the catabolism of iron-containing proteins in the thylakoid membranes; thus, berry skins may need higher concentrations of ferritins to keep free iron concentrations low. This might explain the increase in ferritin transcript abundance with increasing sugar levels.

Most soils contain 2 to $5 \%$ iron including available and unavailable iron; soils with 15 and $25 \mu^{-1} g^{-1}$ of available iron are considered moderate for grapevines [84], but soils with higher concentrations are not considered toxic. Therefore, for both soils in this study, iron concentrations can be considered to be very high but not toxic. The higher available iron concentrations in the BOD vineyard may be associated with the wetter conditions (more reductive conditions) and the lower soil $\mathrm{pH}$.

\section{Environmental influences on transcript abundance in other studies}

Other researchers using Omics approaches have identified environmental factors that influence grape berry transcript abundance and metabolites. One study investigated the differences in transcript abundance in berries of Corvina (a black-skinned grape cultivar that makes red wine) in 11 different vineyards within the same region over 3 years [85]. They determined that approximately $18 \%$ of the berry transcript abundance was affected by the environment. Climate had an overwhelming effect but viticultural practices were also significant. Phenylpropanoid metabolism was very sensitive to the environment and $P A L$ transcript abundance was associated with STS transcript abundance.

In another study of a white grape cultivar, Garganega, berries were analyzed by transcriptomic and metabolomic approaches [86]. Berries were selected from vineyards at different altitudes and soil types. Again, phenylpropanoid metabolism was strongly influenced by the environment. Carotenoid and terpenoid metabolism were influenced as well.

Two studies investigated the grape berry transcriptomes during the ripening phase in two different regions of China, a dry region in Western China and a wet region in Eastern China [87, 88]. These two locations mirror some of the differences in our conditions in our study, namely moisture, light and elevation, although the dry China western region has higher night temperatures and more rainfall than the very dry RNO location. In the Cabernet Sauvignon study [87], they compared the berry transcriptomes (with seeds removed) from the two regions at three different stages: pea size, veraison and maturity. The TSS at maturity was slightly below $20^{\circ}$ Brix. Similar to our study, the response to stimulus, phenylpropanoid and diterpenoid metabolism GO categories were highly enriched in mature berries between the two locations. Differences in the transcript abundance of NCED and PR proteins were also noted. Like in our study, the authors associated the transcript abundance of these proteins to the dry (drought response) and wet (pathogen defense) locations, respectively.

In the second study comparing these two regions in China [88], the effects of the environment on the metabolome and transcriptome of Muscat Blanc à Petits Grains berries were investigated over two seasons; specifically, terpenoid metabolism was targeted. Like in our study, the transcripts in terpenoid were in higher abundance in the wetter location. The transcript abundances were correlated with terpenoid concentrations and a coexpression network was constructed. A specific set of candidate regulatory genes were identified including some terpene synthases (TPS14), glycosyl transferases and 1-hydroxy-2-methyl-2-butenyl 4-diphosphate reductase (HDR). We examined the transcript abundance of some of these candidate genes in our own data but did not find significant differences between our two locations. The contrasting results between our study and Wen et al. (2015) could be for a variety of reasons such as different cultivar responses, berry versus skin samples, or different environmental conditions that affect terpenoid production.

Terpenoid metabolism is influenced by the microclimate [89] and is involved in plant defense responses to pathogens and insects $[29,90]$. Light exposure to Sauvignon Blanc grapes (a white grape cultivar) was manipulated by removing adjacent leaves without any detectable differences in berry temperatures [89]. Increased light exposure increased specific carotenoid and terpene concentrations in the berry. The responses of carotenoid and terpenoid production to temperature are less clear. Some effect of temperature was associated with carotenoid and terpenoid production, but to a lesser extent than light [89]. Higher concentrations of rotundone, a sesquiterpene, have been associated with cooler temperatures [91]. Water deficit can also alter carotenoid and terpenoid metabolism in grapes [11, 92]. Terpenes can act as signals for insect attacks and attract insect predators [90]. Thus, terpenoid metabolism is highly sensitive to the environment and influenced by many factors.

In contrast to these studies, excess light and heat can affect transcript abundance and damage berry quality. In addition to a higher rate of malate catabolism, anthocyanin concentrations and some of the transcript abundances associated with them are decreased as well [93, 94].

\section{Temperature effects on berry maturity and total soluble solids}

BOD berries reached maturity at a lower ${ }^{\circ} \mathrm{Brix}$ level than RNO berries; the cause is likely to be the warmer days and cooler nights in RNO. Higher day temperature may increase photosynthesis and sugar transport and cooler 
night temperatures may reduce fruit respiration. ${ }^{\circ}$ Brix or TSS approximates the \% sugar in a berry and is a reliable marker of berry maturity in any given location [95]; however, TSS is an unreliable marker of berry maturity when comparing grapes from very different climates. The differences in TSS between BOD and RNO are consistent with other studies on the temperature effects on berry development. Indirect studies have associated gradual warming over the last century to accelerated phenology and increased sugar concentrations in the grape berries [96-99]. Increasing temperature can accelerate metabolism, including sugar biosynthesis and transport, but the increase in metabolism is not uniform. For example, the increase in anthocyanin concentration during the ripening phase is not affected as much as the increase in sugar concentration [100]. These responses vary with the cultivar [97], complicating this kind of analysis even further.

Direct studies of temperature effects on Cabernet Sauvignon berry composition also are consistent with our data. In one study, the composition of Cabernet Sauvignon berries was altered substantially for vines grown in phytotrons at 20 or $30^{\circ} \mathrm{C}$ temperatures (temperatures that are very similar to the BOD and RNO temperatures occurring in the present study) [101]. Cooler temperatures promoted anthocyanin development and malate concentrations (inhibited malate catabolism) and higher temperatures promoted TSS ( $\left.{ }^{\circ} \mathrm{Brix}\right)$ and proline concentrations [101]. In a second study, vines were grown at 20 or $30{ }^{\circ} \mathrm{C}$ day temperatures with night temperatures $5{ }^{\circ} \mathrm{C}$ cooler than the day [102]. In this study, higher temperatures increased berry volume and veraison started earlier by about 3 to 4 weeks [102]. The authors concluded that warmer temperatures hastened berry development. In a third study, Cabernet Sauvignon berry composition was affected in a similar manner by soil temperatures that differed by $13^{\circ} \mathrm{C}$ [103].

TSS concentrations are also affected by light and the vine water status. Light is generally not a factor because there is usually a large enough leaf area and sufficient light levels to saturate this source to sink relationship [104, 105]. Sun-exposed Cabernet Sauvignon berries in the vineyard had higher TSS than shaded berries [104]. This sunlight effect was attributed largely to an increase in berry temperature rather than an increase in the fluence rate per se. A higher grapevine water status results in larger berry size and lower sugar concentrations [106] and water deficit is known to increase sugar concentrations in Cabernet Sauvignon [11]. However, temperature is thought to have the largest effect on sugar concentrations [16].

Other transcriptomic data in the present study indicated that BOD berries were more mature at a lower sugar level than RNO berries. These included the transcript abundance profiles of genes involved in autophagy, auxin and ABA signaling, iron homeostasis and seed development. Many of these DEGs had an accelerated rate of change in BOD berries. While these transcripts are in the skins, they may be influenced by signals coming from the seed. In addition, there was a higher transcript abundance for most genes involved with the circadian clock in BOD berries. PHYB can regulate the circadian clock [55] and PHYB activity is very sensitive to night temperatures (BOD had higher night temperatures); $\mathrm{PHYB}$ reversion is accelerated to the inactive form at warmer temperatures [33]. The inactivity of phytochrome promotes the expression of RVE1, which promotes auxin concentrations and seed dormancy [58]. Thus, all things considered, it is likely that temperature and/or the temperature differentials between day and night significantly contributed to the differences in the rate of berry development and sugar accumulation in the two locations.

\section{Are there reliable markers to harvest berries at maturity?}

Determining maturity of grapes is a difficult and error prone process. Reliable markers could aid in the decision of when to harvest the grapes. "Optimum" maturity is a judgement call and will ultimately depend on the winemaker's or grower's specific goals or preferences. A combination of empirical factors can be utilized including ${ }^{\circ}$ Brix, total acidity, berry tasting in the mouth for aroma and tannins, seed color, etc. ${ }^{\circ}$ Brix or total soluble solids by itself may not be the best marker for berry ripening as it appears to be uncoupled from berry maturity by temperature. Phenylpropanoid metabolism, including anthocyanin metabolism, is also highly sensitive to both abiotic and biotic stresses and may not be a good indicator of full maturity. Thus, color may not be a good indicator either. Specific developmental signals from the seed or embryo, such as those involved with auxin and ABA signaling, may provide more reliable markers for berry ripening in diverse environments, but will not be useful in seedless grapes. Aromatic compounds may also be reliable markers but they will need to be generic, developmental markers that are not influenced by the environment. This study revealed many genes that are not reliable markers because they were expressed differently in different environments. One candidate marker that is noteworthy is ATG18G (g071260). Its transcript abundance increased and was relatively linear with increasing ${ }^{\circ}$ Brix and these trends were offset at the two locations relative to their level of putative fruit maturity (Fig. 4). ATG18G is required for the autophagy process [107] and maybe important during the fruit ripening phase. It was found to be a hub gene in a gene subnetwork associated with fruit ripening and chloroplast degradation [4]. Further testing will be required to know if it is essential for fruit ripening and whether its transcript abundance 
is influenced by abiotic and biotic stresses in grape berry skins.

\section{Conclusions}

The ultimate function of a fruit is to produce fully mature seeds in order to reproduce another generation of plants. The ripe berry exhibits multiple traits that signal to other organisms when the fruit is ready for consumption and seed dispersal. In this study, we show that there were large differences in transcript abundance in grape skins in two different locations with different environments, confirming our original hypothesis. We also identified a set of DEGs with common profiles in the two locations. The observations made in this study provide lists of such genes and generated a large number of hypotheses to be tested in the future. WGCNA was particularly powerful and enhanced our analyses. The transcript abundance during the late stages of berry ripening was very dynamic and may respond to many of the environmental and developmental factors identified in this study. Functional analysis of the genes and GO enrichment analysis were very useful tools to elucidate these factors. Some of the factors identified were temperature, moisture, light and biotic stress. The results of this study indicated that berries still have a "sense of place" during the late stages of berry ripening. Future studies are required to follow up on these observations. It appears that fruit ripening is very malleable. Manipulation of the canopy (time and intensity of leaf removal at different locations on the plant) may offer a powerful lever to adjust gene expression and berry composition, since these parameters are strongly affected by light and temperature.

\section{Methods}

\section{Plant materials}

Research approval was obtained by Grant R. Cramer for the Reno grapevines (Vitis vinifera L. cv. Cabernet Sauvignon clone 8), which were grown at the Nevada Agricultural Experiment Station at the University of Nevada, Reno campus. The grapevines were grown on their own roots and were originally obtained as certified material from Inland Desert Nursery, Benton, City, Washington, USA. The grapes were harvested between September 10 and October 2012 depending on maturity at approximately solar noon (plus or minus $1 \mathrm{~h}$ ). ${ }^{\circ}$ Brix was determined using a digital refractometer (HI 96811, Hanna Instruments, Woonsocket, RI, USA). Berry skins were separated by squeezing the berry, the ${ }^{\circ}$ Brix of the juice was simultaneously assessed, and the skins were placed into $50 \mathrm{~mL}$ centrifuge tubes in liquid nitrogen according to sugar level $\left(1 \pm 0.5^{\circ}\right.$ Brix increments; 19 to $27^{\circ}$ Brix). Berries were collected in this way over many days from multiple clusters from multiple vines from three different independently drip-irrigated blocks in the vineyard. Stemwater potentials were measured weekly to assure that the irrigation levels sufficiently maintained the water status of the vines. The vines were regularly sprayed for fungal prevention. Each block in the vineyard was considered an experimental replicate. Soil testing was performed by A \& L Western Agricultural Laboratories (Modesto, CA, USA).

In BOD, they used Cabernet Sauvignon clone CA33 412, which was grown on $\mathrm{SO} 4$ rootstock. These grapevines were grown at the VitAdapt vineyard at the Institut National de Recherche Agronomique (INRA) research station (Villenave d'Ornon, France). There were five replicate blocks within this site to mitigate soil variation. Additional details of the VitAdapt project can be found in [108]. Berries for the three replicates were collected at the 14:00 $\mathrm{h}$ of the day. Environmental conditions and variables of the Reno and BOD vineyards are listed in Table 1 . The vines were regularly sprayed for fungal prevention. Soil testing was performed by Aurea Agroscience (Blanquefort, France).

\section{RNA extraction}

In RNO, the total RNA was extracted from berry skins at 20, 22, 24 and $26^{\circ} \mathrm{Brix}$ (three experimental replicates each), and the quantity and quality was assessed, as previously described [109] from approximately $250 \mathrm{mg}$ of frozen, finely ground, skin tissue.

In BOD, total RNA from berry skins at 19.5, 20.5, 21.5 and $22.5^{\circ}$ Brix was extracted from three experimental replicates each according to Reid et al. [110] from $1 \mathrm{~g}$ of frozen, finely ground berry skins. DNAse I treatment was performed on the RNA extracts according to the manufacturer's instructions (Ambion TURBO DNA-free DNase, Life Technologies). The quality of the RNA was verified with a $1.8 \%$ agarose gel and quantified with a Nanodrop 2000c spectrophotometer (Thermo Scientific).

\section{RNA-Seq library preparation and sequencing}

Barcoded libraries (50 bp single-end) were produced from the RNA of the Cabernet Sauvignon berry skins using Illumina TruSeq RNA library prep kits (Illumina Inc., San Diego, CA, USA) and sequenced by the Neuroscience Genomics Core at the University of California, Los Angeles for the RNO samples and by the Genome Center at the University of California, Davis for the BOD samples using Illumina TruSeq chemistry (version 3.0) with a HiSeq2000 sequencer (Illumina Inc., San Diego, CA, USA).

\section{Transcript abundance and statistical analysis}

FastQC [111] was used to produce fastq files and to inspect and verify the sequence quality. Trimommatic [112] version 0.36 was used to trim the Illumina adapters from the sequences. Salmon [24] version 0.14.1 was used to estimate the transcript abundance from the trimmed fastq 
files with settings of - -gcBias, - -seqBias, - -fldMean $=50$, --fldSD = 1, --validateMappings --rangeFactorizationBins 4. An augmented hybrid fasta file was built from the Vitis vinifera cv. Cabernet Sauvignon genome [26] using generateDecoyTranscriptome.sh from salmontools. This file was used to build the index file used for the quantification with a k-mer size of 15 . The salmon output (quant files) was imported into DESeq2 [27] version 1.22.2 using tximport version 1.10.1 [113] for determination of differentially expressed genes (DEGs).

\section{Coexpression network analysis}

WGCNA version $1.68[114,115]$ was used for constructing the gene networks using all of the libraries for each location. Low-expressed genes were removed with a minimum threshold of 10 counts in all libraries prior to analysis. The varianceStabilizingTransformation function of the DESeq2 package was used to transform the counts data and the blockwiseModules function of the DESeq2 package was used to construct the gene networks (gene modules). An adjacency matrix was produced using an optimized biweight mid-correlation with the following settings: $\beta$ equal to 8 and maxPoutliers parameter equal to 0.05 . Gene modules were detected with the DynamicTreecut algorithm using the following settings: minimal module size equal to 30 and branch merge cut height equal to 0.25 . The module eigengenes produced from this analysis were used to determine the association of the gene modules (22) with various experimental traits (e.g. ${ }^{\circ}$ Brix and locations).

\section{Gene functional annotation additions}

Gene models of the Cabernet Sauvignon annotation were searched against different protein databases with the blastx function of the DIAMOND version 0.9.19 software [116] using default parameters and reporting alignments in the $1 \%$ range of the top alignment score. For each gene model, the best blast hit was kept (1-to-1) and reported in addition of the current annotation. For multiple hits with the same score (1-to-many), the first hit was kept as the representative result but the other hits are still accessible. The databases used were Araport11, release 06.17.16, [117] and the Vitis vinifera IGGP 12X from EnsemblPlants 38, a part of EnsemblGenomes [118]. The corresponding gene annotations were obtained from the Araport11 gff file (release 06.22.16), TAIR10 functional descriptions (release 01.16.13) and a manually curated and actualized grapevine V1 annotation of PN40024.

\section{Functional enrichment of $\mathrm{GO}$ categories}

Gene Ontology (GO) enrichment was performed using topGO version 2.34.0 [119]. Enriched functional categories with an FDR adjusted $p$-value $>0.01$ after the Fisher's test were filtered for further analysis. For gene ontology
(GO) categories assignments, the GO already present in the Cabernet Sauvignon annotation file [25] were combined with the previously manually curated GO annotations of the PN40024 V1 gene models. The GO from P40024 were attributed to the Cabernet Sauvignon gene model if the blast hit was presenting a percentage of identity greater than $95 \%$ as well as an alignment representing more than $95 \%$ of the length of both the query and the subject.

\section{Supplementary information}

Supplementary information accompanies this paper at https://doi.org/10. 1186/s12870-020-2251-7. Additional file 1. $\log _{2}$ transcripts per million (TPM) to genes uniquely
mapped to the $V 1$ Cabernet Sauvignon genome.

Additional file 2. Differentially expresses genes (DEGs) determined by DESeq2 for berry skin samples at $22^{\circ}$ Brix from BOD and RNO.

Additional file 3. Statistical results from gene set enrichment analysis of the DEGs using topGO.

Additional file 4. Image of the top 25 connected GO categories in the topGO network of the DEGs in Additional file 3.

Additional file 5. Common genes between BOD and RNO from transcriptomic approaches 2 and 3.

Additional file 6. Module membership (MM) of all filtered transcripts as defined by WGCNA. Values are the KME (module eigengene connectivity).

Additional file $\mathbf{7}$ Heatmap correlation of berry traits ( ${ }^{\circ}$ Brix level, BOD, RNO) of each of 19 gene modules. Gene modules were identified by a color name (MMcolornumber) as assigned by the WGCNA R package. Values in each heatmap block are the correlation (left value) and $p$-value (in parentheses) of the module with the berry trait.

Additional file 8. topGO analysis of all modules with genes having a $\mathrm{kME}>0.80$. The results for each module are on a separate tab within the file.

Additional file 9. topGO analysis of the top 400 genes with the greatest differential expression between high and low ${ }^{\circ}$ Brix samples in BOD berry skins.

Additional file 10. topGO analysis of the top 400 genes with the greatest differential expression between high and low ${ }^{\circ}$ Brix samples in RNO berry skins.

Additional file 11. Representative examples of transcript profiles of some stilbene synthase (STS) genes that were differentially expressed.

Additional file 12. Transcript abundance of circadian clock genes from $\mathrm{BOD}$ and RNO berry skins. The data are placed on a circadian clock model derived from [4]. Lines in the model represent known interactions between genes; red arrows are positive interactions, black lines are negative interactions, and blue lines indicate direct physical interactions but the direction, positive or negative, is unknown. No lines indicate that there are no known interactions at this time. Transcript profiles outlined in red highlight significantly higher transcript abundance for the BOD berries.

Additional file 13. A model of the peripheral genes including light sensing genes that interact with core circadian clock genes in BOD and RNO berry skins. Lines represent gene interactions as described in Additional file 12. Red and blue lightning bolts represent the reception of their respective light wavelengths for each gene symbol. Transcript profiles outlined in red highlight significantly higher transcript abundance for the BOD berries.

Additional file 14. Transcript profiles of ABA biosynthesis and signaling genes that are differentially expressed between BOD and RNO berry skins. 


\section{Abbreviations}

ABA: ABscisic Acid; ABCG: Adenosine triphosphate Binding Casette G; ABF: Abscisic acid responsive elements Binding Factor; ABS: Abnormal Shoot; ACO1: ACc Oxidase 1; ACOL: ACc Oxidase-Like; APG9: AutoPhaGy 9; ARAC1: Arabidopsis RAC-like 1; ARF: Auxin Response Factor; ATG: AuTophaGy; ATH: Arabidopsis thaliana abc2 Homolog; BAM: Barley Any Meristem; BCAT: Branched-Chain-amino-acid AminoTransferase; BOD: BOrDeaux; bp: base pair; BSMT1: Benzoate/Salicylate MethylTransferase 1; CBF1: C-repeat/DRE Binding Factor 1; CCA1: Circadian Clock Associated 1; CLE: CLavata3/Esr-related; CML: CalModulin-Like; COP1: COnstitutive Photomorphogenic 1; CRY3: CRYptochrome 3; cv: cultivar; CYSB: Cystatin B; DEG(s): Differentially Expressed Gene(s); DHS: 3-deoxy-D-arabinoHeptulosonate 7-phosphate Synthase; DMAPP: DiMethylAllyl diPhosPhate; DUF642: Domain of Unknown Function 642; DXR: 1-deoxy-D-Xylulose 5phosphate Reductoisomerase; EC: Evening Complex; EE: Evening Element: EIN: Ethylene INsensitive; ELF: EarLy Flowering; ERF: Ethylene Response Factor; EXL2: EXordium Like 2; FAR1: Far-Red impaired Response 1; FDR: False Discovery Rate; FER: FERrittin; FOP1: FOlded Petal 1; FRS: FAR1-Related Sequence; GH3: GH3 family protein; GIDB1: Gibberellic acid Insensitive Dwarf1B; GO: Gene Ontology; HAD: HaloAcid Dehalogenase-like hydrolase protein; HB12: HomeoBox 12; HDS: 4-Hydroxy-3-methylbut-2-en-1-yl Diphosphate Synthase; IAA: Indole Acetic Acid; IDD14: InDeterminateDomain 14; IPP: IsoPentenyl Pyrophosphate; IREG: Iron REGulated; JAR: JAsmonate Resistant; LHY: Late elongated Hypocotyl; MAT3: Methionine AdenosylTransferase 3; MEP: MethylErythritol 4-Phosphate; MLA: Intracellular MiLdew A: NAC073: NAC domain containing protein 73: NCBI: National Center for Biotechnology Information; NCED: Nine-Cis Epoxycarotenoid Dioxygenase; NRAMP3: Natural Resistance-Associated Macrophage Protein 3; PAL: PhenylAlanine Lyase; PCL1: PhytoCLock 1; PHY: PHYtochrome; PIF: Phytochrome Interacting Factor; PR: Pathogenesis Related; PRR: PsuedoResponse Regulator; PSY: Phytoene SYnthase; RNO: ReNO; ROS: Reactive Oxygen Species; RVE1: ReVeillE 1; SA: Salicylic Acid; SIA: Salt Induced Abc kinase; SnRK: SNF1 Related protein Kinase; STS: STilbene Synthase; SULTR: SULfate TRansporter; TAIR: The Arabidopsis Information Resource; TAT: TyrosineAmino Transferase; TOC: Timing Of Cab expression; TPL: ToPLess; TPM: Transcripts Per Million; TPPD: Trehalose Phosphate Phosphatase D; TPS: TerPene Synthase; TSS: Total Soluble Solids; VIT: Vacuolar Iron Transporter; WGCNA: Weighted Gene Co-expression Network Analysis; XTH: Xyloglucan endoTransglucosylase/Hydrolase; YSL: Yellow Stripe-Like

\section{Acknowledgements}

We would like to thank Aude Habran for her assistance in collecting berry skins and RNA extraction of BOD berries and thank the many UNR Biochemistry senior thesis undergraduate students that assisted in berry separation in the RNO berries.

\section{Authors' contributions}

GRC, SD, and AD-I designed the experiments. RG collected berries in RNO, analyzed the ${ }^{\circ} B r i x$ levels and extracted the RNA. The original data were analyzed with the PN40024 genome annotation by GRC, but NC updated the analysis with the new Cabernet Sauvignon genome annotation, performed the WGCNA and assisted with estimation of the TPMs. GRC processed and analyzed the data and wrote the body of the paper. All authors reviewed, edited and approved the final version of the manuscript.

\section{Funding}

The design of the study, the collection and processing of the berry samples, the analysis and interpretation of the data, and the writing of the manuscript were supported by the University of Nevada, Reno, Agriculture Experimental Station with the Multi-state USDA-Hatch Grant NEV00383A to GRC.

\section{Availability of data and materials}

RNA-Seq data were deposited with the Sequence Read Archive (SRA) database at the National Center for Biotechnology Information (NCBI) with the SRA accession number PRJNA260535 [120] for the RNO data and SRP149949 for the BOD data.

Ethics approval and consent to participate Not applicable.

\section{Consent for publication}

Not applicable.

\section{Competing interests}

The authors declare that they have no competing interests. The first author is a section editor of BMC Plant Biology. The first author had no role in the editorial process

\section{Author details}

'Department of Biochemistry and Molecular Biology, University of Nevada, Reno, NV 89557, USA. '2UMR Ecophysiology and Grape Functional Genomics, Institut des Sciences de la Vigne et du Vin, University of Bordeaux, Villenave d'Ornon, France.

Received: 20 May 2019 Accepted: 14 January 2020

Published online: 28 January 2020

\section{References}

1. This $P$, Lacombe $T$, Thomas MR. Historical origins and genetic diversity of wine grapes. Trends Genet. 2006;22(9):511-9. https://doi.org/10.1016/j.tig. 2006.07.008.

2. Kuhn N, Guan L, Dai ZW, Wu BH, Lauvergeat V, Gomes E, Li SH, Godoy F, Arce-Johnson P, Delrot S. Berry ripening: recently heard through the grapevine. J Exp Bot. 2014;65(16):4543-59. https://doi.org/10.1093/jxb/ ert395.

3. Fortes AM, Teixeira RT, Agudelo-Romero P. Complex interplay of hormonal signals during grape berry ripening. Molecules. 2015;20(5):9326-43. https:// doi.org/10.3390/molecules20059326.

4. Ghan R, Petereit J, Tillett RL, Schlauch KA, Toubiana D, Fait A, Cramer GR. The common transcriptional subnetworks of the grape berry skin in the late stages of ripening. BMC Plant Biol. 2017;17(1):94. https://doi.org/10.1186/ s12870-017-1043-1.

5. Gonzalez-Barreiro C, Rial-Otero R, Cancho-Grande B, Simal-Gandara J. Wine aroma compounds in grapes: a critical review. Crit Rev Food Sci Nutr. 2015; 55(2):202-18. https://doi.org/10.1080/10408398.2011.650336.

6. Boss PK, Kalua CM, Nicholson EL, Maffei SM, Böttcher C, Davies C. Fermentation of grapes throughout development identifies stages critical to the development of wine volatile composition. Aust J Grape Wine Res. 2018;24(1):24-37. https://doi.org/10.1111/ajgw.12296.

7. Boss PK, Pearce AD, Zhao Y, Nicholson EL, Dennis EG, Jeffery DW. Potential grape-derived contributions to volatile ester concentrations in wine. Molecules. 2015;20(5):7845-73. https://doi.org/10.3390/molecules20057845.

8. Dennis EG, Keyzers RA, Kalua CM, Maffei SM, Nicholson EL, Boss PK. Grape contribution to wine aroma. Production of hexyl acetate, octyl acetate and benzyl acetate during yeast fermentation is dependent upon precursors in the must. J Agric Food Chem. 2012;60:2638-41. https://doi.org/10.1021/ jf2042517.

9. Sun P, Schuurink RC, Caissard JC, Hugueney P, Baudino S. My way: noncanonical biosynthesis pathways for plant volatiles. Trends Plant Sci. 2016;21(10):884-94. https://doi.org/10.1016/j.tplants.2016.07.007.

10. Schwab W, Wust M. Understanding the Constitutive and induced biosynthesis of mono- and Sesquiterpenes in grapes (Vitis vinifera): a key to unlocking the biochemical secrets of unique grape aroma profiles. J Agric Food Chem. 2015;63(49):10591-603. https://doi.org/10.1021/acs.jafc.5b04398.

11. Deluc LG, Quilici DR, Decendit A, Grimplet J, Wheatley MD, Schlauch KA, Merillon JM, Cushman JC, Cramer GR. Water deficit alters differentially metabolic pathways affecting important flavor and quality traits in grape berries of cabernet sauvignon and chardonnay. BMC Genomics. 2009;10:212. https://doi.org/10.1186/1471-2164-10-212.

12. Cramer GR, Evans J, Ardelean R, Keady M, Quilici D, Schooley DA. Impacts of regulated-deficit irrigation on the flavor components of grapes and wines. In: Jeandet P, Clément C, Conreaux A, editors. Macromolecules and Secondary Metabolites of Grapevine and Wine. Paris: Lavoisier; 2007. p. 539.

13. Koundouras S, Marinos V, Gkoulioti A, Kotseridis Y, van Leeuwen C. Influence of vineyard location and vine water status on fruit maturation of nonirrigated cv. Agiorgitiko (Vitis vinifera L.). effects on wine phenolic and aroma components. J Agric Food Chem. 2006;54:5077-86.

14. Drappier J, Thibon C, Rabot A, Geny-Denis L. Relationship between wine composition and temperature: impact on Bordeaux wine typicity in the 
context of global warming-review. Crit Rev Food Sci Nutr. 2017:1-17. https://doi.org/10.1080/10408398.2017.1355776.

15. van Leeuwen $C$, Friant $P$, Choné $X$, Tregoat $O$, Koundouras S, Dubourdieu D. Influence of climate, soil, and cultivar on Terroir. Am J Enol Vitic. 2004;55(3):207.

16. Martínez-Lüscher J, Kizildeniz T, Vučetić V, Dai Z, Luedeling E, van Leeuwen C, Gomès E, Pascual I, Irigoyen JJ, Morales F, Delrot S. Sensitivity of grapevine phenology to water availability, temperature and $\mathrm{CO} 2$ concentration. Front Environ Sci. 2016:4:48.

17. Bokulich NA, Collins TS, Masarweh C, Allen G, Heymann H, Ebeler SE, Mills DA. Associations among Wine Grape Microbiome, Metabolome, and Fermentation Behavior Suggest Microbial Contribution to Regional Wine Characteristics. mBio. 2016;7(3). https://doi.org/10.1128/mBio.00631-16.

18. Berdeja M, Nicolas P, Kappel C, Dai ZW, Hilbert G, Peccoux A, Lafontaine M, Ollat N, Gomès E, Delrot S. Water limitation and rootstock genotype interact to alter grape berry metabolism through transcriptome reprogramming. Hort Res. 2015;2:15012. https://doi.org/10.1038/hortres.2015.12.

19. Marè C, Aprile A, Roncaglia E, Tocci E, Corino LG, De Bellis L, Cattivelli L. Rootstock and soil induce transcriptome modulation of phenylpropanoid pathway in grape leaves. J Plant Interact. 2013;8(4):334-49. https://doi.org/ 10.1080/17429145.2012.754958

20. Cookson SJ, Ollat N. Grafting with rootstocks induces extensive transcriptional re-programming in the shoot apical meristem of grapevine. BMC Plant Biol. 2013;13:147. https://doi.org/10.1186/1471-2229-13-147.

21. Corso M, Vannozzi A, Ziliotto F, Zouine M, Maza E, Nicolato T, Vitulo N, Meggio F, Valle G, Bouzayen M, Müller M, Munné-Bosch S, Lucchin M, Bonghi C. Grapevine rootstocks differentially affect the rate of ripening and modulate Auxin-related genes in cabernet sauvignon berries. Front Plant Sci. 2016;7:69

22. Cochetel N, Escudie F, Cookson SJ, Dai Z, Vivin P, Bert PF, Munoz MS, Delrot S, Klopp C, Ollat N, Lauvergeat V. Root transcriptomic responses of grafted grapevines to heterogeneous nitrogen availability depend on rootstock genotype. J Exp Bot. 2017;68(15):4339-55. https://doi.org/10.1093/jxb/ erx224.

23. Fabres PJ, Collins C, Cavagnaro TR, Rodriguez Lopez CM. A concise review on multi-Omics data integration for Terroir analysis in Vitis vinifera. Front Plant Sci. 2017;8:1065. https://doi.org/10.3389/fpls.2017.01065.

24. Patro R, Duggal G, Love MI, Irizarry RA, Kingsford C. Salmon provides fast and bias-aware quantification of transcript expression. Nat Methods. 2017; 14(4):417-9. https://doi.org/10.1038/nmeth.4197.

25. Minio A, Massonnet M, Figueroa-Balderas R, Vondras AM, Blanco-Ulate B, Cantu D. Iso-Seq Allows Genome-Independent Transcriptome Profiling of Grape Berry Development. G3 (Bethesda). 2019;9(3):755-67. https://doi.org/ 10.1534/g3.118.201008.

26. Chin CS, Peluso P, Sedlazeck FJ, Nattestad M, Concepcion GT, Clum A, Dunn C, O'Malley R, Figueroa-Balderas R, Morales-Cruz A, Cramer GR, Delledonne M, Luo C, Ecker JR, Cantu D, Rank DR, Schatz MC. Phased diploid genome assembly with single-molecule real-time sequencing. Nat Methods. 2016; 13(12):1050-4. https://doi.org/10.1038/nmeth.4035.

27. Love Ml, Huber W, Anders S. Moderated estimation of fold change and dispersion for RNA-seq data with DESeq2. Genome Biol. 2014;15(12):1-21. https://doi.org/10.1186/s13059-014-0550-8.

28. Guo P, Li Z, Huang P, Li B, Fang S, Chu J, Guo H. A tripartite amplification loop involving the transcription factor WRKY75, salicylic acid, and reactive oxygen species accelerates leaf senescence. Plant Cell. 2017;29(11):2854-70. https://doi.org/10.1105/tpc.17.00438.

29. Martin DM, Aubourg S, Schouwey MB, Daviet L, Schalk M, Toub O, Lund ST, Bohlmann J. Functional annotation, genome organization and phylogeny of the grapevine (Vitis vinifera) terpene synthase gene family based on genome assembly, FLcDNA cloning, and enzyme assays. BMC Plant Biol. 2010;10:226. https://doi.org/10.1186/1471-2229-10-226.

30. Dudareva N, Martin D, Kish CM, Kolosova N, Gorenstein N, Faldt J, Miller B, Bohlmann J. (E)-beta-ocimene and myrcene synthase genes of floral scent biosynthesis in snapdragon: function and expression of three terpene synthase genes of a new terpene synthase subfamily. Plant Cell. 2003;15(5): 1227-41.

31. Young PR, Lashbrooke JG, Alexandersson E, Jacobson D, Moser C, Velasco R, Vivier MA. The genes and enzymes of the carotenoid metabolic pathway in Vitis vinifera L. BMC Genomics. 2012;13:243. https://doi.org/10.1186/14712164-13-243.

32. Jung J-H, Domijan M, Klose C, Biswas S, Ezer D, Gao M, Khattak AK, Box MS, Charoensawan V, Cortijo S, Kumar M, Grant A, Locke JCW, Schäfer E, Jaeger
KE, Wigge PA. Phytochromes function as thermosensors in Arabidopsis. Science. 2016;354(6314):886.

33. Legris M, Klose C, Burgie ES, Rojas CC, Neme M, Hiltbrunner A, Wigge PA, Schafer E, Vierstra RD, Casal JJ. Phytochrome B integrates light and temperature signals in Arabidopsis. Science. 2016;354(6314):897-900. https:// doi.org/10.1126/science.aaf5656.

34. Tattersall EA, Grimplet J, Deluc L, Wheatley MD, Vincent D, Osborne C, Ergul A, Lomen E, Blank RR, Schlauch KA, Cushman JC, Cramer GR. Transcript abundance profiles reveal larger and more complex responses of grapevine to chilling compared to osmotic and salinity stress. Funct Integr Genomics. 2007;7(4):317-33.

35. Jaglo-Ottoson KR, Gilmour SJ, Zarka DG, Schabenberger O, Thomashow MF. Arabidopsis CBF1 overexpression induces COR genes and enhances freezing tolerance. Science. 1998;280:104-6.

36. Seo PJ, Kim MJ, Ryu JY, Jeong EY, Park CM. Two splice variants of the IDD14 transcription factor competitively form nonfunctional heterodimers which may regulate starch metabolism. Nat Commun. 2011;2:303. https://doi.org/ 10.1038/ncomms1303.

37. Zhang $X$, Liu S, Takano T. Two cysteine proteinase inhibitors from Arabidopsis thaliana, AtCYSa and AtCYSb, increasing the salt, drought, oxidation and cold tolerance. Plant Mol Biol. 2008;68(1-2):131-43. https:// doi.org/10.1007/s11103-008-9357-x.

38. Fung RW, Gonzalo M, Fekete C, Kovacs LG, He Y, Marsh E, McIntyre LM, Schachtman DP, Qiu W. Powdery mildew induces defense-oriented reprogramming of the transcriptome in a susceptible but not in a resistant grapevine. Plant Physiol. 2008;146(1):236-49. https://doi.org/10.1104/pp.107. 108712.

39. Davies C, Boss PK, Robinson SP. Treatment of grape berries, a nonclimacteric fruit with a synthetic auxin, retards ripening and alters the expression of developmentally regulated genes. Plant Physiol. 1997;115: 1155-61.

40. Böttcher C, Boss PK, Davies C. Delaying Riesling grape berry ripening with a synthetic auxin affects malic acid metabolism and sugar accumulation, and alters wine sensory characters. Funct Plant Biol. 2012;39(9):745. https://doi. org/10.1071/fp12132.

41. Cramer GR. Abiotic stress \& plant responses from the whole vine to the genes. Aust J Grape Wine Res. 2010;16:86-93.

42. Tan BC, Joseph LM, Deng WT, Liu L, Li QB, Cline K, McCarty DR. Molecular characterization of the Arabidopsis 9-cis epoxycarotenoid dioxygenase gene family. Plant J. 2003:35(1):44-56.

43. Frey A, Effroy D, Lefebvre V, Seo M, Perreau F, Berger A, Sechet J, To A, North HM, Marion-Poll A. Epoxycarotenoid cleavage by NCED5 fine-tunes ABA accumulation and affects seed dormancy and drought tolerance with other NCED family members. Plant J. 2012;70(3):501-12. https://doi.org/10. 1111/j.1365-313X.2011.04887.x.

44. Rattanakon S, Ghan R, Gambetta GA, Deluc LG, Schlauch KA, Cramer GR. Abscisic acid transcriptomic signaling varies with grapevine organ. BMC Plant Biol. 2016;16(1):72. https://doi.org/10.1186/s12870-016-0763-y.

45. Hopper DW, Ghan R, Schlauch KA, Cramer GR. Transcriptomic network analyses of leaf dehydration responses identify highly connected $A B A$ and ethylene signaling hubs in three grapevine species differing in drought tolerance. BMC Plant Biol. 2016;16(1):118. https://doi.org/10.1186/s12870016-0804-6.

46. Takahashi F, Suzuki T, Osakabe Y, Betsuyaku S, Kondo Y, Dohmae N, Fukuda H, Yamaguchi-Shinozaki K, Shinozaki K. A small peptide modulates stomatal control via abscisic acid in long-distance signalling. Nature. 2018;556(7700): 235-8. https://doi.org/10.1038/s41586-018-0009-2.

47. Broekaert WF, Delaure SL, De Bolle MF, Cammue BP. The role of ethylene in host-pathogen interactions. Annu Rev Phytopathol. 2006:44:393-416. https://doi.org/10.1146/annurev.phyto.44.070505.143440.

48. Dubois $M$, Van den Broeck L, Inze D. The pivotal role of ethylene in plant growth. Trends Plant Sci. 2018;23(4):311-23. https://doi.org/10.1016/j.tplants. 2018.01.003

49. Liu M, Pirrello J, Chervin C, Roustan JP, Bouzayen M. Ethylene control of fruit ripening: revisiting the complex network of transcriptional regulation. Plant Physiol. 2015;169(4):2380-90. https://doi.org/10.1104/pp.15.01361.

50. Chang KN, Zhong S, Weirauch MT, Hon G, Pelizzola M, Li H, Huang SS, Schmitz RJ, Urich MA, Kuo D, Nery JR, Qiao H, Yang A, Jamali A, Chen H, Ideker T, Ren B, Bar-Joseph Z, Hughes TR, Ecker JR. Temporal transcriptional response to ethylene gas drives growth hormone cross-regulation in Arabidopsis. Elife. 2013;2:e00675. https://doi.org/10.7554/eLife.00675. 
51. Van den Broeck L, Dubois M, Vermeersch M, Storme V, Matsui M, Inze D. From network to phenotype: the dynamic wiring of an Arabidopsis transcriptional network induced by osmotic stress. Mol Syst Biol. 2017; 13(12):961. https://doi.org/10.15252/msb.20177840.

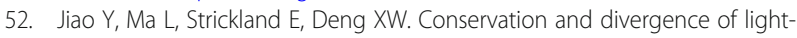
regulated genome expression patterns during seedling development in rice and Arabidopsis. Plant Cell. 2005;17(12):3239-56. https://doi.org/10.1105/tpc. 105.035840 .

53. Hu W, Su YS, Lagarias JC. A light-independent allele of phytochrome B faithfully recapitulates photomorphogenic transcriptional networks. Mol Plant. 2009;2(1):166-82. https://doi.org/10.1093/mp/ssn086.

54. Delker C, van Zanten M, Quint M. Thermosensing enlightened. Trends Plant Sci. 2017;22(3):185-7. https://doi.org/10.1016/j.tplants.2017.01.007.

55. Hsu PY, Harmer SL. Wheels within wheels: the plant circadian system. Trends Plant Sci. 2014;19(4):240-9. https://doi.org/10.1016/j.tplants.2013.11. 007.

56. Johansson $M$, Staiger D. Time to flower: interplay between photoperiod and the circadian clock. J Exp Bot. 2015;66(3):719-30. https://doi.org/10.1093/jxb/ eru441.

57. Huang H, Alvarez S, Bindbeutel R, Shen Z, Naldrett MJ, Evans BS, Briggs SP, Hicks LM, Kay SA, Nusinow DA. Identification of evening complex associated proteins in Arabidopsis by affinity purification and mass spectrometry. Mol Cell Proteomics. 2016;15(1):201-17. https://doi.org/10.1074/mcp. M115. 054064

58. Jiang $Z$, Xu G, Jing $Y$, Tang W, Lin R. Phytochrome B and REVEILLE1/2mediated signalling controls seed dormancy and germination in Arabidopsis. Nat Commun. 2016;7:12377. https://doi.org/10.1038/ ncomms12377.

59. Leivar P, Monte E, Al-Sady B, Carle C, Storer A, Alonso JM, Ecker JR, Quail PH. The Arabidopsis phytochrome-interacting factor PIF7, together with PIF3 and PIF4, regulates responses to prolonged red light by modulating phyB levels. Plant Cell. 2008;20(2):337-52. https://doi.org/10.1105/tpc.107.052142.

60. Kidokoro S, Maruyama K, Nakashima K, Imura Y, Narusaka Y, Shinwari ZK, Osakabe Y, Fujita Y, Mizoi J, Shinozaki K, Yamaguchi-Shinozaki K. The phytochrome-interacting factor PIF7 negatively regulates DREB1 expression under circadian control in Arabidopsis. Plant Physiol. 2009;151(4):2046-57. https://doi.org/10.1104/pp.109.147033.

61. Rawat R, Schwartz J, Jones MA, Sairanen I, Cheng Y, Andersson CR, Zhao Y, Ljung K, Harmer SL. REVEILLE1, a Myb-like transcription factor, integrates the circadian clock and auxin pathways. PNAS. 2009;106(39):16883-8. https://doi. org/10.1073/pnas.0813035106.

62. Gupta SK, Sharma S, Santisree P, Kilambi HV, Appenroth K, Sreelakshmi Y, Sharma R. Complex and shifting interactions of phytochromes regulate fruit development in tomato. Plant Cell Environ. 2014;37(7):1688-702. https://doi. org/10.1111/pce.12279

63. Kuhn N, Ormeno-Nunez J, Jaque-Zamora G, Perez FJ. Photoperiod modifies the diurnal expression profile of VVPHYA and VVPHYB transcripts in fieldgrown grapevine leaves. J Plant Physiol. 2009;166(11):1172-80. https://doi. org/10.1016/j.jplph.2009.01.005.

64. Stockinger EJ, Gilmour SJ, Thomashow MF. Arabidopsis thaliana CBF1 encodes an AP2 domain-containing transcriptional activator that binds to the C-repeat/DRE, a cis-acting DNA regulatory element that stimulates transcription in response to low temperature and water deficit. PNAS. 1997; 94(February):1035-40.

65. Tillett RL, Wheatley MD, Tattersall EA, Schlauch KA, Cramer GR, Cushman JC. The Vitis vinifera C-repeat binding protein 4 (VVCBF4) transcriptional factor enhances freezing tolerance in wine grape. Plant Biotechnol J. 2012;10(1): 105-24. https://doi.org/10.1111/j.1467-7652.2011.00648.x.

66. Nakashima K, Yamaguchi-Shinozaki K. ABA signaling in stress-response and seed development. Plant Cell Rep. 2013;32(7):959-70. https://doi.org/10. 1007/s00299-013-1418-1

67. Nicolas P, Lecourieux D, Kappel C, Cluzet S, Cramer G, Delrot S, Lecourieux $F$. The basic leucine zipper franscription factor ABSCISIC ACID RESPONSE ELEMENT-BINDING FACTOR2 is an important transcriptional regulator of abscisic acid-dependent grape berry ripening processes. Plant Physiol. 2014; 164(1):365-83. https://doi.org/10.1104/pp.113.231977.

68. Wang R, Estelle M. Diversity and specificity: auxin perception and signaling through the TIR1/AFB pathway. Curr Opin Plant Biol. 2014;21:51-8. https:// doi.org/10.1016/j.pbi.2014.06.006.

69. Wang L, Hua D, He J, Duan $Y$, Chen Z, Hong X, Gong Z. Auxin response Factor2 (ARF2) and its regulated homeodomain gene HB33 mediate abscisic acid response in Arabidopsis. PLoS Genet. 2011;7(7):e1002172. https://doi.org/10.1371/journal.pgen.1002172.

70. Jeandet P, Douillet-Breuil AC, Bessis R, Debord S, Sbaghi M, Adrian M. Phytoalexins from the Vitaceae: biosynthesis, phytoalexin gene expression in transgenic plants, antifungal activity, and metabolism. J Agric Food Chem. 2002;50(10):2731-41.

71. Dufour MC, Magnin N, Dumas B, Vergnes S, Corio-Costet MF. Highthroughput gene-expression quantification of grapevine defense responses in the field using microfluidic dynamic arrays. BMC Genomics. 2016;17(1): 957. https://doi.org/10.1186/s12864-016-3304-z.

72. Jacobs AK, Dry IB, Robinson SP. Induction of different pathogenesis-related CDNAs in grapevine infected with powdery mildew and treated with ethephon. Plant Pathol. 1999;48(3):325-36.

73. Belhadj A, Telef N, Cluzet S, Bouscaut J, Corio-Costet MF, Merillon JM. Ethephon elicits protection against Erysiphe necator in grapevine. J Agric Food Chem. 2008;56(14):5781-7. https://doi.org/10.1021/jf800578c.

74. Dixon RA, Paiva NL. Stress-induced Phenylpropanoid metabolism. Plant Cell. 1995;7(7):1085-97. https://doi.org/10.1105/tpc.7.7.1085.

75. Huang J, Gu M, Lai Z, Fan B, Shi K, Zhou YH, Yu JQ, Chen Z. Functional analysis of the Arabidopsis PAL gene family in plant growth, development, and response to environmental stress. Plant Physiol. 2010;153(4):1526-38. https://doi.org/10.1104/pp.110.157370.

76. Shi P, Li B, Chen H, Song C, Meng J, Xi Z, Zhang Z. Iron Supply Affects Anthocyanin Content and Related Gene Expression in Berries of Vitis vinifera cv. Cabernet Sauvignon. Molecules. 2017;22(2). https://doi.org/10.3390/ molecules22020283.

77. Manara A, DalCorso G, Leister D, Jahns P, Baldan B, Furini A. AtSIA1 AND AtOSA1: two Abc1 proteins involved in oxidative stress responses and iron distribution within chloroplasts. New Phytol. 2014;201(2):452-65. https://doi. org/10.1111/nph.12533.

78. Chen CC, Chien WF, Lin NC, Yeh KC. Alternative functions of Arabidopsis yellow stripe-Like3: from metal translocation to pathogen defense. PLoS One. 2014;9(5):e98008. https://doi.org/10.1371/journal.pone.0098008.

79. Chu HH, Chiecko J, Punshon T, Lanzirotti A, Lahner B, Salt DE, Walker EL. Successful reproduction requires the function of Arabidopsis yellow stripeLike1 and yellow stripe-Like3 metal-nicotianamine transporters in both vegetative and reproductive structures. Plant Physiol. 2010;154(1):197-210. https://doi.org/10.1104/pp.110.159103.

80. Ravet K, Touraine B, Boucherez J, Briat JF, Gaymard F, Cellier F. Ferritins control interaction between iron homeostasis and oxidative stress in Arabidopsis. Plant J. 2009;57(3):400-12. https://doi.org/10.1111/j.1365-313X. 2008.03698.x.

81. Ravet K, Touraine B, Kim SA, Cellier F, Thomine S, Guerinot ML, Briat JF, Gaymard F. Post-translational regulation of AtFER2 ferritin in response to intracellular iron trafficking during fruit development in Arabidopsis. Mol Plant. 2009;2(5):1095-106. https://doi.org/10.1093/mp/ssp041.

82. Conte S, Stevenson D, Furner I, Lloyd A. Multiple antibiotic resistance in Arabidopsis is conferred by mutations in a chloroplast-localized transport protein. Plant Physiol. 2009;151(2):559-73. https://doi.org/10.1104/pp.109. 143487.

83. Xu XM, Adams S, Chua NH, Moller SG. AtNAP1 represents an atypical SufB protein in Arabidopsis plastids. J Biol Chem. 2005;280(8):6648-54. https://doi. org/10.1074/jbc. M413082200.

84. Moyer MM, Singer SD, Davenport JR, Hoheisel G-A. Vineyard nutrient Management in Washington State. Pullman: Washington State University Extension; 2018. p. 1-45.

85. Dal Santo S, Tornielli GB, Zenoni S, Fasoli M, Farina L, Anesi A, Guzzo F, Delledonne M, Pezzotti M. The plasticity of the grapevine berry transcriptome. Genome Biol. 2013;14(6):r54. https://doi.org/10.1186/gb-201314-6-r54.

86. Dal Santo S, Fasoli M, Negri S, D'Inca E, Vicenzi N, Guzzo F, Tornielli GB, Pezzotti $M$, Zenoni S. Plasticity of the berry ripening program in a white grape variety. Front Plant Sci. 2016;7:970. https://doi.org/10.3389/fpls.2016.00970.

87. Sun R, He F, Lan Y, Xing R, Liu R, Pan Q, Wang J, Duan C. Transcriptome comparison of cabernet sauvignon grape berries from two regions with distinct climate. J Plant Physiol. 2015;178:43-54. https://doi.org/10.1016/j. jplph.2015.01.012.

88. Wen YQ, Zhong GY, Gao Y, Lan YB, Duan CQ, Pan QH. Using the combined analysis of transcripts and metabolites to propose key genes for differential terpene accumulation across two regions. BMC Plant Biol. 2015;15:240. https://doi.org/10.1186/s12870-015-0631-1. 
89. Young PR, Eyeghe-Bickong HA, du Plessis K, Alexandersson E, Jacobson DA, Coetzee Z, Deloire A, Vivier MA. Grapevine plasticity in response to an altered microclimate: sauvignon Blanc modulates specific metabolites in response to increased berry exposure. Plant Physiol. 2016;170(3):1235-54. https://doi.org/10.1104/pp.15.01775.

90. Singh B, Sharma RA. Plant terpenes: defense responses, phylogenetic analysis, regulation and clinical applications. 3 Biotech. 2015;5(2):129-51. https://doi.org/10.1007/s13205-014-0220-2.

91. Zhang P, Barlow S, Krstic M, Herderich M, Fuentes S, Howell K. Withinvineyard, within-vine, and within-bunch variability of the Rotundone concentration in berries of Vitis vinifera L. cv. Shiraz. J Agric Food Chem. 2015;63(17):4276-83. https://doi.org/10.1021/acs.jafc.5b00590.

92. Ou C, Du X, Shellie K, Ross C, Qian MC. Volatile compounds and sensory attributes of wine from cv. Merlot (Vitis vinifera L.) grown under differential levels of water deficit with or without a kaolin-based, foliar reflectant particle film. J Agric Food Chem. 2010;58(24):12890-8. https://doi.org/10. 1021/jf102587x

93. Degu A, Ayenew B, Cramer GR, Fait A. Polyphenolic responses of grapevine berries to light, temperature, oxidative stress, abscisic acid and jasmonic acid show specific developmental-dependent degrees of metabolic resilience to perturbation. Food Chem. 2016;212:828-36. https://doi.org/10. 1016/j.foodchem.2016.05.164

94. Rienth M, Torregrosa L, Luchaire N, Chatbanyong R, Lecourieux D, Kelly MT, Romieu C. Day and night heat stress trigger different transcriptomic responses in green and ripening grapevine (vitis vinifera) fruit. BMC Plant Biol. 2014;14:108. https://doi.org/10.1186/1471-2229-14-108.

95. Bonada M, Sadras VO. Review: critical appraisal of methods to investigate the effect of temperature on grapevine berry composition. Aust J Grape Wine Res. 2015;21(1):1-17. https://doi.org/10.1111/ajgw.12102.

96. Bock A, Sparks TH, Estrella N, Menzel A. Climate-induced changes in grapevine yield and must sugar content in Franconia (Germany) between 1805 and 2010. PLoS One. 2013;8(7):e69015. https://doi.org/10.1371/journal. pone.0069015

97. Petrie PR, Sadras VO. Advancement of grapevine maturity in Australia between 1993 and 2006: putative causes, magnitude of trends and viticultural consequences. Aust J Grape Wine Res. 2008;14(1):33-45. https:// doi.org/10.1111/j.1755-0238.2008.00005.x.

98. Jones GV, Davis RE. Climate influences on grapevine phenology, grape composition, and wine production and quality for Bordeaux, France. Am J Enol Vitic. 2000;51(3):249-61.

99. Duchêne $\mathrm{E}$, Schneider C. Grapevine and climatic changes: a glance at the situation in Alsace. Agron Sustain Dev. 2005;25(1):93-9.

100. Sadras VO, Moran MA. Elevated temperature decouples anthocyanins and sugars in berries of shiraz and cabernet franc. Aust J Grape Wine Res. 2012; 18(2):115-22. https://doi.org/10.1111/j.1755-0238.2012.00180.x.

101. Buttrose MS, Hale CR, Kliewer WM. Effect of temperature on the composition of 'cabernet sauvignon' berries. Am J Enol Vitic. 1971;22(2):71.

102. Guillaumie S, Fouquet R, Kappel C, Camps C, Terrier N, Moncomble D, Dunlevy JD, Davies C, Boss PK, Delrot S. Transcriptional analysis of late ripening stages of grapevine berry. BMC Plant Biol. 2011;11:165. https://doi. org/10.1186/1471-2229-11-165

103. Zelleke A, Kliewer WM. Influence of root temperature and rootstock on Budbreak, shoot growth, and fruit composition of cabernet sauvignon grapevines grown under controlled conditions. Am J Enol Vitic. 1979;30(4): 312.

104. Bergqvist J, Dokoozlian N, Ebisuda N. Sunlight exposure and temperature effects on berry growth and composition of cabernet sauvignon and Grenache in the Central San Joaquin Valley of California. Am J Enol Vitic. 2001;52(1):1.

105. Kliewer WM, Dokoozlian NK. Leaf area/crop weight ratios of grapevines: influence on fruit composition and wine quality. Am J Enol Vitic. 2005;56(2): 170.

106. Triolo R, Roby JP, Plaia A, Hilbert G, Buscemi S, Di Lorenzo R, van Leeuwen C. Hierarchy of factors impacting grape berry mass: separation of direct and indirect effects on major berry metabolites. Am J Enol Vitic. 2018;69(2):103.

107. Liu Y, Bassham DC. Autophagy: pathways for self-eating in plant cells. Annu Rev Plant Biol. 2012;63:215-37. https://doi.org/10.1146/annurev-arplant042811-105441.

108. Destrac-Irvine A, Van Leeuwen C. The VitAdapt project: extensive phenotyping of a wide range of varieties in order to optimize the use of genetic diversity within the Vitis vinifera species as a tool for adaptation to a changing environment. Villnave D'Ornon: Vigne \& Vin Publications Internationales; 2017.

109. Ghan R, Van Sluyter SC, Hochberg U, Degu A, Hopper DW, Tillet RL, Schlauch KA, Haynes PA, Fait A, Cramer GR. Five omic technologies are concordant in differentiating the biochemical characteristics of the berries of five grapevine (Vitis vinifera L.) cultivars. BMC Genomics. 2015;16(1):946. https://doi.org/10.1186/s12864-015-2115-y.

110. Reid KE, Olsson N, Schlosser J, Peng F, Lund ST. An optimized grapevine RNA isolation procedure and statistical determination of reference genes for real-time RT-PCR during berry development. BMC Plant Biol. 2006;6:27. https://doi.org/10.1186/1471-2229-6-27.

111. Andrews S: FastQC. 2014. https://www.bioinformatics.babraham.ac.uk/ projects/fastqc/. Accessed 19 Mar 2018.

112. Bolger AM, Lohse $M$, Usadel B. Trimmomatic: a flexible trimmer for Illumina sequence data. Bioinformatics. 2014;30(15):2114-20. https://doi.org/10.1093/ bioinformatics/btu170.

113. Soneson C, Love MI, Robinson MD. Differential analyses for RNA-seq: transcript-level estimates improve gene-level inferences. F1000Res. 2015;4 1521. https://doi.org/10.12688/f1000research.7563.2.

114. Langfelder P, Horvath S. WGCNA: an R package for weighted correlation network analysis. BMC Bioinformatics. 2008;9:559. https://doi.org/10.1186/ 1471-2105-9-559.

115. Langfelder P, Horvath S. Fast R Functions for Robust Correlations and Hierarchical Clustering. J Stat Softw. 2012;46(11):i11. https://www.ncbi.nlm. nih.gov/pmc/articles/PMC3465711/.

116. Buchfink $B$, Xie $C$, Huson DH. Fast and sensitive protein alignment using DIAMOND. Nat Methods. 2014;12:59. https://doi.org/10.1038/nmeth.3176.

117. Cheng CY, Krishnakumar V, Chan AP, Thibaud-Nissen F, Schobel S, Town CD Araport11: a complete reannotation of the Arabidopsis thaliana reference genome. Plant J. 2017;89(4):789-804. https://doi.org/10.1111/tpj.13415.

118. Kersey PJ, Allen JE, Allot A, Barba M, Boddu S, Bolt BJ, Carvalho-Silva D, Christensen M, Davis P, Grabmueller C, Kumar N, Liu Z, Maurel T, Moore B, McDowall MD, Maheswari U, Naamati G, Newman V, Ong CK, Paulini M, Pedro H, Perry E, Russell M, Sparrow H, Tapanari E, Taylor K, Vullo A, Williams G, Zadissia A, Olson A, et al. Ensembl genomes 2018: an integrated omics infrastructure for non-vertebrate species. Nucleic Acids Res. 2018;46(D1): D802-8. https://doi.org/10.1093/nar/gkx1011.

119. topGO: Enrichment Analysis for Gene Ontology. R package version 2.36.0. [http://www.mpi-sb.mpg.de/ alexa]. Accessed 15 Aug 2019.

120. Leinonen $R$, Sugawara $H$, Shumway M. International nucleotide sequence database C: the sequence read archive. Nucleic Acids Res. 2011;39(Database issue):D19-21. https://doi.org/10.1093/nar/gkq1019.

\section{Publisher's Note}

Springer Nature remains neutral with regard to jurisdictional claims in published maps and institutional affiliations.

\section{Ready to submit your research? Choose BMC and benefit from:}

- fast, convenient online submission

- thorough peer review by experienced researchers in your field

- rapid publication on acceptance

- support for research data, including large and complex data types

- gold Open Access which fosters wider collaboration and increased citations

- maximum visibility for your research: over $100 \mathrm{M}$ website views per year

At BMC, research is always in progress.

Learn more biomedcentral.com/submission 